\title{
Able but Unwilling to Enforce: Cooperative Dilemmas in Group Lending ${ }^{1}$
}

\author{
Nicholas Sabin \\ Universidad de Santiago de Chile \\ Felix Reed-Tsochas \\ University of Oxford
}

\begin{abstract}
It is known that greater social cohesion increases a group's ability to enforce cooperation. Despite this, defectors often go unpunished, and groups with social structures that are a priori favorable often fail. A critical distinction is required between the structural effect on ability versus willingness to punish. The authors develop a theoretical framework in which variation in a group's social structure generates a tension between ability and willingness to enforce cooperation. Structures that promote ability to punish also often reduce interest in carrying out sanctions, thus changing collective outcomes. The authors' empirical analysis involves a well-defined cooperative dilemma: group lending in Sierra Leone. They complement statistical modeling, based on a data set containing 5,487 group repayments, with ethnographic analysis. They find that (1) structural cohesion only increases economic cooperation between borrowers to a point, beyond which unwillingness outweighs increased ability to punish, reducing group repayments, and that (2) groups with disconnected subgroups perform worse on average. Although borrowers are more willing to punish defectors in the out-subgroup, they are unable to do so effectively.
\end{abstract}

A key factor promoting collective action is the ability to sanction those who are not cooperating (Olson 1965; Ostrom 1999). Without a central authority to

${ }^{1}$ The authors would like to thank Delia Baldassarri, David Barron, Michael Biggs, Ronald Burt, Matthew Jackson, Christopher Marcum, Thomas Powell, Tom Snijders, Peter Tufano, Brian Uzzi, and the AJS reviewers for extremely valuable feedback at

(C) 2020 by The University of Chicago. All rights reserved. 0002-9602/2020/12506-0004\$10.00 
administer sanctions, groups often rely on informal punishments or rewards, for example, through the loss of reputation or ostracism (Oliver 1980; Heckathorn 1990). It intuitively follows that groups with greater social connectedness will have a greater ability to punish defectors effectively, resulting in improved collective outcomes (Homans 1950; Coleman 1990). However, this intuition can be fundamentally misleading if the effect on a group's willingness to enforce is not explicitly considered. ${ }^{2}$

To illustrate the difference, consider group lending. It is a common financial practice offered to low-income clients that presents a clear cooperative dilemma (Anthony 2005; Armendáriz and Morduch 2010). A group of borrowers enter into a joint-liability contract under which each member receives an equal portion of a loan. If one of the group members does not repay, the entire group is held responsible by the lending institution, losing access to future credit. For each borrower there is an incentive to free ride and leave the financial burden with the other members. This situation typifies what is referred to as the "first-order cooperative dilemma," the temptation to share in the benefits of a collective good without personally contributing to it. In this context, it is often expected that well-connected groups would be better able to sanction potential defaulters, for example, through social pressure or public shaming (Besley and Coate 1995; Wydick 1999). However, empirical research attempting to map the social structure of microcredit groups to their collective repayment has been highly contradictory (see Hermes and Lensink [2007] for a review).

The potential problem has been more broadly identified in the sociology literature: highly cohesive groups often fail at collective action (Gould 1993; Portes and Sensenbrenner 1993; Flache and Macy 1996; Anthony 2005). This poor performance may stem from the group's unwillingness to carry out the social enforcement. In informal groups, enforcement is a public good in itself (Yamagishi 1986). This raises what is referred to as the "second-order cooperative dilemma," the temptation to share in the collective benefits of norm enforcement without personally contributing to enforcement (Oliver 1980).

various stages of this research and on previous drafts of this article. Support was provided by the Department of Management of the Faculty of Management and Economics at the Universidad de Santiago de Chile, the Saiid Business School at the University of Oxford, the European Commission through the 7th Framework FET-Open Project FOC-II (grant 255987), the Oxford Martin School (grant LC1213-006), the Oxford University Centre for Corporate Reputation, and the Skoll Centre for Social Entrepreneurship. Direct correspondence to Felix Reed-Tsochas, Saïd Business School, Park End Street, Oxford OX1 1HP, United Kingdom. E-mail: felix.reed-tsochas@sbs.ox.ac.uk

${ }^{2}$ In this article, the terms "social structure" and "social connectedness" are used to refer generally to the number, quality, and arrangement of a group's social relations as commonly conceptualized in the sociology and social network literatures (Granovetter 1985; Wasserman and Faust 1994). More specific concepts, e.g., structural cohesion or disconnected subgroups, will be formalized in this article in relation to specific measures and hypotheses. 
Consider the group lending example again. Each group member faces two basic cooperative dilemmas (Heckathorn 1993): Should she contribute her financial portion of the loan (first-order dilemma), and should she contribute to sanctioning a delinquent group member (second-order dilemma)? Does the nature of her relationships to the other group members affect the likelihood that she will carry out one or both tasks? In other contexts, researchers have noted that, while increased social connectedness may mitigate the first-order dilemma, it may potentially exacerbate the second-order dilemma (Flache and Macy 1996; Hechter and Opp 2001; Horne 2004).

This problem introduces a fundamental question underlying collective efficacy, not just restricted to the case of highly cohesive groups. Does variation in social structure produce systematic effects on the relationship between the ability and willingness to enforce cooperation? We suspect that this is a common and widespread tension that results from basic underlying mechanisms driven by social interaction. For example, relationships with more frequent interaction provide more opportunities for sanctioning but also typically reduce the interest in carrying out the punishment. This tension arises in myriad cooperative contexts, ranging from opportunities to punish team members violating work productivity norms (Homans 1974) to chastising community members not active in political movements (Chong 1991). If we can better distinguish the structural tendencies regarding ability and willingness to enforce cooperation, we can better understand how social context shapes collective outcomes.

In the first half of this article, we develop a theoretical framework in which variation in a group's social structure may simultaneously mitigate the first-order dilemma while exacerbating the second-order dilemma. This fits with an active line of research in which scholars have called for progress beyond the idea that social interaction enhances cooperation to distinguish how and when structure may trigger multiple, potentially conflicting, mechanisms (Gould 2003; Cook, Levi, and Hardin 2009; Baldassarri 2015). We approach this theoretically by first separating the structural effects on ability and willingness to enforce. Once these are disentangled, we attempt to put them back together, in order to understand which behaviors are most likely to dominate collective levels of cooperation (Fehr and Gintis 2007). A key implication of the theoretical framework is that there are causal reasons, stemming from the underlying group structure, why ability and willingness will often be in conflict. The tension may be so central to cooperative behavior that if willingness is not incorporated in one's expectations, the estimates for the effect of social structure on the collective outcome may be incorrect, in terms of both magnitude as well as direction.

Having substantiated that a group's ability and willingness may often be in conflict, a second implication of the framework regards how this conflict should be integrated into our expectations for collective outcomes. 
Researchers have noted that for sanctioning to act as a cooperation-enhancing mechanism, both ability and willingness are necessary (Ostrom 2000; Reuben and Riedl 2013). Ability and willingness may be actual or perceived, but if one is viewed as lacking, the value of the sanctioning system will be weak. We argue that for different group structures, the lesser of the two enforcement factors will determine the extent that sanctions can improve the group outcome. For example, although a joint-liability group may have extensive opportunities to shame delinquent borrowers, if it is well known that the group is not willing to follow through, the ability has minimal effect on promoting repayment (Al-Azzam, Hill, and Sarangi 2012). Conversely, if group members are highly willing to shame delinquent borrowers but meaningful opportunities to do so are not available because of limited social interaction, the excess of willingness will have a minimal effect.

This approach for incorporating differential tendencies in ability and willingness to enforce allows us to make refutable hypotheses regarding the cooperative outcomes for specific group structures. Specifically, we examine (1) structural cohesion, a measure of a group's average connectedness (Burt 1987; Coleman 1988); (2) the existence of disconnected subgroups, a measure of structural variation within the overall group (Festinger, Schachter, and Back 1950; Frank and Yasumoto 1998); and (3) the interaction of these two structural features.

In the second half of this article, we provide an in-depth empirical analysis of economic cooperation using mixed methods. The context is group lending in Sierra Leone. Here, group members must make cooperative decisions with high-value stakes, for example, between damaging long-term relationships and forgoing crucial sums of money. The combination of quantitative and qualitative methods enables us statistically to test broad cooperative patterns while also explicating the underlying "social cogs and wheels" (Hedström and Bearman 2009, p. 17).

We test the hypothesized relationships using an empirical data set provided by a microfinance institution. The design is nested with each subset including greater detail on the social mechanisms of interest (Small 2011). The largest sample includes 1,884 borrowers involved in 5,487 group repayment transactions spanning the period from 2006 to 2011. At the highest level, the quantitative analysis involves group structures based on highresolution spatial data, individual borrower characteristics, and fine-grained group outcomes. The analysis also offers a methodological contribution, demonstrating how individual-level global positioning system (GPS) spatial coordinates can be used to construct proxies for a group's social structure. At the midlevel, we test for construct validity using social network data collected on a subset of borrowers. Finally, at the most granular subset we examine ethnographic data on borrower behavior in lending groups. We explore the structural constraints and enforcement processes of 64 borrowers 
in their own words. While the analyses at the higher levels allow us to test our hypotheses and show the statistical significance of the findings, the qualitative inquiry enhances our understanding of the causal linkages (see King, Keohane, and Verba 1994; Small 2013). The benefits of the mixed-methods design in this study can be categorized as both "confirmatory" (i.e., triangulation of data types to ensure that the findings do not depend primarily on the particular kind of data collected) as well as "complementary" (i.e., combining data types to compensate for the specific interpretation challenges of the other data type; Small 2011).

The analysis supports three substantive relationships. (1) We found that structural cohesion only increases economic cooperation to a point, beyond which unwillingness to punish outweighs the benefits of increased ability, resulting in statistically worse group repayment. Although enforcement leniency is often described as an exception for a friend, the consistency of exceptions in the borrower interviews provides intuitive examples of why highly cohesive groups perform worse on average. (2) We also examined the abilitywillingness tension in regard to a different structural measure: the existence of disconnected subgroups. This occurs when groups are internally divided so that members are well connected within subgroups but not between subgroups. For example, this might arise if two subgroups work in different trading markets on a daily basis. We found that the disconnected structure accentuated out-group bias and increased the willingness to punish members of the other subgroup. One might expect that this increase in willingness would improve cooperation overall. But at the same time, the disconnect weakened the ability to effectively punish the other subgroup. As hypothesized, the net effect was that the performance of groups with disconnected subgroups was worse statistically than for those groups without disconnected subgroups. This highlights that a structural variant typically affects both ability and willingness and that the collective outcome is driven by the lesser of the two factors. (3) The empirical results also confirmed a significant positive interaction effect between overall group cohesion and the existence of disconnected subgroups. This implies that the marginal benefit of structural cohesion is more substantial if a group contains disconnected subgroups. Stated alternatively, groups with a disconnect between subgroups are more prone to a collapse in cooperation; their decline in performance as overall cohesion weakens is more severe. Overall, the results indicate how structural forces promote counteracting tendencies regarding ability and willingness to enforce. The trade-offs are systematic, allowing one to better estimate collective outcomes that are nonmonotonic and sensitive to interaction effects.

More broadly, our work contributes to the literature that seeks to relate structural measures of embeddedness to social capital held by actors (Granovetter 1973; Coleman 1988; Portes 1998). In particular, collective action and successful mobilization in social groups remain highly salient topics 
within the field of sociology (Olson 1965; Gould 1993; Heckathorn 1993; Baldassarri 2015). Whereas our specific findings may be particular to the context that we have studied, the social mechanisms that we identify are quite general in nature, and their consequences should be observable more broadly. "Will I punish a group member?" is a simple question that reveals a much more complex interaction of personal and structural factors. By dissecting a group's structure in more detail, such as considering variation within the substructure, one can clarify not only how social mechanisms are in conflict but also how systematic behaviors emerge.

\section{THEORY AND HYPOTHESES}

\section{Group Lending and the Foundations of Social Collateral}

To formulate our hypotheses, we draw on cooperation research across disciplines, as well as studies specific to the group lending context. The intent is to use a well-defined cooperative context to illustrate the importance of the theoretical distinction between ability and willingness to enforce, before turning to a wider literature on collective action.

In group lending, "social collateral" refers to the use of borrower's relationships as security against loan default (Besley and Coate 1995). Group lending makes explicit use of social collateral by having clients enter into a joint-liability contract. This means that, from the perspective of the lending institution, the group members share a collective outcome. For example, if the group is unwilling to repay for a defecting member, the financial institution does not attempt to distinguish who failed to contribute. If the loan is not paid in full, all of the group members lose access to future loans. This loan structure produces a social dilemma in which there is a tension between the interests of the individual (i.e., to leave the repayment burden with the other members) and of the group (i.e., maintain collective access to future credit; Anthony 2005). ${ }^{3}$ Such group contracts have been a key feature of the microfinance movement over the last four decades and have played a role in extending financial services to impoverished populations historically excluded from the financial market (Armendáriz and Morduch 2010). The global spread of group lending has produced numerous cultural adaptations based on organizational formality, group size, and membership criteria, to name just a few variations (Huppi and Feder 1990; Hermes and Lensink 2007).

\footnotetext{
${ }^{3}$ Social dilemmas possess two characteristics: (1) the payoff to individuals for defecting behavior is greater than the payoff for cooperative behavior, regardless of what other group members do, and (2) all individuals receive a lesser payoff if all defect than if all cooperate (Dawes 1980).
} 
Group lending's mixing of social mechanisms with economic incentives has attracted significant attention from social scientists. Seminal works by anthropologists (Geertz 1962; Ardener 1964) considered the theoretical basis of social collateral in the context of rotating savings and credit associations, an informal predecessor to joint-liability contracts. They noted that group repayment was driven by strong community relationships and the avoidance of public shame. Repayment was conceptualized as a matter of "honour" or "solemn duty" (Ardener 1964, p. 216). Hechter (1988) extended this work by exploring how norms of social control emerge and are institutionalized in these groups.

Subsequent research has attempted to examine how variation in social interdependence affects group repayment in more formal joint-liability groups. Theorists drawing on development economics, typically employing a rational choice framework for group members, have focused on the concepts of peer monitoring (Stiglitz 1990; Varian 1990), the ability to informally sanction defecting members (Besley and Coate 1995), and selective interaction and screening by peers (Ghatak 1999). Scholars drawing on economic sociology have explored group outcomes in which agent behavior may not be limited to self-interest, such as enhanced group identity and solidarity (Anthony 2005), social capital and trust (Woolcock 2001), and group gender composition (Anthony and Horne 2003).

A number of empirical studies relating social interdependence to group repayment have produced contradictory findings, in which they have found positive, insignificant, and even negative relationships (e.g., Zeller 1998; Wydick 1999; Paxton, Graham, and Thraen 2000; Ahlin and Townsend 2007; Karlan 2007). The studies often employ different methods, which makes direct comparisons difficult. However, basic unresolved questions, such as the expected benefits and hindrances of group cohesion on repayment, suggest that our understanding of social collateral may be flawed or incomplete (see Hermes and Lensink [2007] for a review).

We argue that our understanding of social collateral would be greatly enhanced by expounding the critical tension between ability and willingness to enforce in cooperative dilemmas (Oliver 1980; Axelrod 1986; Heckathorn 1993). The existing literature on social collateral has primarily focused on how interdependence influences the first-order cooperative dilemma, for example, how a socially connected microcredit group has a greater ability to sanction and increase the cost to a defaulting member. However, if one attempts to map social structure to collective outcomes without distinguishing the change in willingness, predictions will be misleading. Some scholars have specifically emphasized that willingness to enforce should be incorporated as a key theoretical factor in group credit (Anthony 2005; Ahlin and Townsend 2007; Paal and Wiseman 2011). 
In discussions with practitioners such as the management and loan officers of several microfinance institutions, they were consistently surprised by the extent that highly cohesive groups were underperforming compared to their expectations. They were well aware that groups unwilling to enforce could cause repayment problems, but it had appeared to be a separate issue from a group's social structure. In the following sections, we theoretically delineate how variation in a group's structure produces conflicting, but predictable, pressures on enforcement behavior.

\section{Structural Cohesion and Compliance Enforcement}

The starting point of our theoretical framework is social embeddedness, the concept that economic activity is submerged in a system of social relations (Polanyi 1944; Granovetter 1985). This provides scaffolding on which we can link structural forces with economic cooperation. Specifically, we focus on two structural features of a group's embeddedness: structural cohesion and disconnected subgroups. While cohesion provides us with an average measure of a group's connectedness, characterization of heterogeneity within the group is also of value. Structural variation within the group can be well characterized by the existence (or the lack thereof) of disconnected subgroups with strong internal connections (Frank and Yasumoto 1998). For example, two lending groups may have the same average level of structural cohesion, but one could have connections distributed equally and the other unequally, resulting in two factions. By considering these different measures, we can gauge whether structural features produce more general enforcement trade-offs.

To clarify the influence on specific social behaviors, we will theoretically examine the structural effect on enforcement ability separately from the structural effect on enforcement willingness, before considering the combined effect. Table 1 summarizes the logical structure of the propositions and hypotheses. Propositions 1a, 2a, and 3 a characterize the relationship

TABLE 1

Structure of Propositions and Hypotheses

\begin{tabular}{lccc}
\hline \hline & \multicolumn{3}{c}{ Enforcement Behavior } \\
\cline { 2 - 4 } & Ability to & Willingness to & $\begin{array}{c}\text { Net Effect on } \\
\text { Enforce }\end{array}$ \\
Structural Feature & Enforce & Enforcement \\
\hline $\begin{array}{l}\text { Structural cohesion......... } \\
\text { Disconnected subgroups.... }\end{array}$ & Proposition 1a & Proposition 1b & Hypothesis 1 \\
$\begin{array}{l}\text { Interaction effect: } \\
\text { cohesion } \times \text { disconnected. . }\end{array}$ & Proposition 3a & Proposition 3b & Hypothesis 3 \\
\hline
\end{tabular}


between a structural feature and the ability to enforce. Propositions 1b, $2 \mathrm{~b}$, and $3 \mathrm{~b}$ characterize the relationship between a structural feature and the willingness to enforce. Building on the propositions, hypotheses 1, 2, and 3 formalize the expected relationship between a structural feature and the net effect of enforcement on cooperation.

The cohesion of groups has been studied extensively and conceptualized in numerous ways, often to highlight different context-specific features (e.g., Durkheim 1893; Albert 1953; Bourdieu 1986; Bettenhausen 1991; Putnam 1993). Intuitively, the structural aspect of cohesion reflects a group's level of connectedness (Frank 1996; Moody and White 2003; Friedkin 2004). Researchers have often operationalized cohesion with structural measures such as tie density (Homans 1950; Burris 2005), for example, the proportion of actual friendships in a group relative to the potential number of friendships, and multiplicity of tie types (Blau 1964; Lazega and Pattison 1999; Uzzi 1999), for example, the number of ways in which group members are connected (social, kinship, work, etc.).

Extensive research suggests that there is a positive relationship between cohesion and cooperation (Homans 1950; Olson 1965; Marwell and Oliver 1993; Kim and Bearman 1997). The finding that groups of well-connected actors exhibit cooperative benefits in comparison to groups of weakly connected actors has received such support that it can almost be considered a sociological truism (Flache 2002). A key element of the relationship is that cohesion increases the opportunity to sanction group members, as well as the effectiveness of sanctions (Coleman 1988; Heckathorn 1990; Portes and Sensenbrenner 1993; Fehr and Gintis 2007). By "sanction," we are referring to "a punishment (or reward) enacted on the basis of a social agreement that a given course of action ought (or ought not) occur" (Hechter and Opp 2001, p. 403). Furthermore, by "ability to sanction" we are referring to both the opportunity to sanction and its potential effectiveness. ${ }^{4}$ To ground this analysis in microfinance, informal social sanctions in a microcredit group typically involve peer pressure expressed as pestering or cajoling delinquent members in the marketplace or in their homes; public shaming or tarnishing their reputations; and ostracism, both in social terms as well as exclusion from future business activities (Montgomery 1996; Rankin 2002; Brett 2006).

However, there is more disagreement among scholars regarding the motives that might link cohesion with sanctioning. Models based on rational choice assume that actors are primarily self-interested and that cohesion changes the fundamental costs and benefits of the dilemma: more frequent interaction increases the practical opportunities to apply sanctions (Voss

\footnotetext{
${ }^{4}$ One could formally model the difference between sanction opportunities and their efficacy (e.g., Heckathorn 1990). For the purpose of this article, we focus on the distinction between ability (both in terms of opportunity and potential effectiveness) vs. the willingness to act.
} 
2001; Lin 2002); greater public awareness of behavior increases the value of reputation (Coleman 1988; Ostrom and Walker 2003); the risk of damaging multiplex relationships that provide other benefits (social or economic) increases the cost of defection (Brass, Butterfield, and Skaggs 1998; GómezGardeñes et al. 2012).

By contrast, models based on symbolic interaction assume that actors are primarily motivated by meanings and identities (Tajfel 1974; Turner 1982). Increased group solidarity and identity can promote the development of group norms for sanctioning, increase the psychological weight of a sanction, and facilitate moralizing and coercion (Abrams and Hogg 1998; Portes 1998; Horne 2007).

Notably, the motives for social interaction may vary, but the expectations for sanctioning effectiveness are not in conflict. Here, both rational and normative motives suggest a similar positive relationship between structural cohesion and an increased ability to effectively enforce compliance. Before considering willingness to enforce, there is substantial theory and empirical evidence to formalize the following proposition:

PROPOSITION 1a.-As a group's structural cohesion increases, the ability to enforce compliance increases, ceteris paribus.

If the ability to enforce were the only enforcement factor linking cohesion and cooperation, we would expect increased cohesion to consistently improve collective outcomes. In the context of microfinance, this suggests that increased structural cohesion should enhance social collateral as security against group loan default.

Despite the intuitive benefits of cohesion, there is a long history of evidence for highly cohesive groups producing worse collective outcomes (Durkheim 1893; Weber [1922] 1978; Gould 1993; Entwisle et al. 2007). Flache and Macy (1996, p. 3) pointedly stated that the obvious benefits of highly cohesive groups have "obscured a potentially devastating weakness of strong ties." This effect could have severe implications for the expected value of social collateral for microfinance, as it is often based on highly cohesive groups of borrowers.

Scholars have noted that without centralized authority, the enforcement of compliance norms on defectors is a public good in itself (Yamagishi 1986). The second-order cooperative dilemma refers to the incentive to partake in the benefits of enforcement while allowing others to bear the enforcement expense (Oliver 1980). If too many actors free ride on enforcement, the threat of punishment declines, and the first-order problem is exacerbated. This emphasizes that the value of social collateral backing a group loan derives not just from an ability to enforce but from a willingness of group members to do so.

Flache and Macy (1996) argue that a key source of the enforcement dilemma is structural. In highly cohesive groups social control flows into the maintenance of interpersonal relationships at the expense of compliance 
with group obligations. Their argument is an extension of the cohesioncompliance framework (Homans 1974; Coleman 1990), in which cohesive groups are more dependent on each other for social approval and are more willing to trade compliance for approval. Flache and Macy's (1996) cohesionresistance framework augments the model by not limiting actors to dissimilar resources (i.e., actors can engage in exchanging approval for approval). Actors in a highly cohesive group may value social approval more than compliance, providing a structural disincentive for enforcement.

The disincentive for enforcement can arise from both game-theoretic and norm-based arguments. In a highly cohesive group, the cost of sanctioning may increase as a result of damaging valuable reciprocal relationships. For example, a member may be delinquent on the group loan but also regularly looks after other members' children. A greater risk of counterpunishment could also increase the perceived cost (Nikiforakis 2008). As the total cost of sanctioning increases, rational choice models predict a decrease in sanctioning (Anderson and Putterman 2006; Carpenter 2007). A reduced willingness to enforce may also be motivated by conflicting norms. "Norms do not exist in splendid isolation; instead they are linked in various ways to other norms" (Hechter and Opp 2001, p. 401). Cohesive groups may have norms against punishment of its members. For example, one may be expected to show leniency to well-connected friends.

The reduction in enforcement is most likely to occur under certain conditions. A critical contextual feature is the value of the social connections in relation to the benefit of the collective good (Oliver 1980; Yamagishi and Takahashi 1994; Horne 2007). For highly embedded ties, the incremental benefit in social approval resulting from contributions to the particular good may be small in relative terms (Flache and Macy 1996). The balance may also lean toward nonenforcement if increased social interdependence does not increase the value of the collective good (Horne 2004; Anthony 2005). Past social history may also exacerbate weak enforcement if actors have already entered into a behavioral pattern of trading approval for approval (Flache and Macy 1996).

In the context of microfinance, empirical evidence suggests that the scope conditions that increase the risk of highly cohesive groups may be prevalent. The formation of groups with highly embedded social ties are often promoted by microfinance institutions (e.g., group members that have been long-term neighbors and know each other in multiple social contexts; Schreiner 2001; Hermes and Lensink 2007), resulting in a higher value of the social relationships relative to the loan contract from the perspective of borrowers. Theory and evidence support formalizing the following relationship.

PROPOSITION 1b.-As a group's structural cohesion increases, the willingness to enforce compliance decreases, ceteris paribus. 
This suggests that if the only enforcement factor linking cohesion and cooperation were willingness, then increased cohesion would have a negative effect on cooperation.

Forming expectations for the collective outcome is now more difficult as propositions $1 \mathrm{a}$ and $1 \mathrm{~b}$ indicate that these enforcement factors may often be in opposition. As a group becomes more cohesive, ability increases while willingness declines and vice versa. What relationship should we then expect between structural cohesion and a group's cooperative outcome? Do changes in ability and willingness cancel each other out or produce some other effect on cooperation?

To build appropriate expectations, a key point is that a group's ability and willingness to enforce should not be viewed as independent additive factors contributing to cooperation. Rather, we argue that both ability and willingness are necessary conditions for social sanctions to positively influence collective behavior; neither condition is independently sufficient (see Mill 1882). As both are necessary, an excess of one cannot offset a lack of the other. Field and experimental research has shown that for sanctioning to serve as a collective action enhancing mechanism, both effective opportunities and (perceived) willingness to sanction must be present (Ostrom 2000; Reuben and Riedl 2013). Note this does not mean sanctions must be carried out; threats of sanctions are known to influence cooperative behavior. However, the threat must be credible; that is, there must be perceived willingness.

For example, consider a group structure that results in high ability to enforce but low willingness (numerous opportunities to sanction but agreed norms not to sanction). The net result is not a moderate level of (expected) enforcement. The most likely behavior is low enforcement because it is known that the group is not likely to carry out the sanctions. Alternatively, if a group is very willing to sanction but has a low structural ability to do so, the inability to sanction will be the limiting factor. The extra willingness on its own does not enhance cooperation. Structures that produce willingness without ability, or vice versa, will not benefit from the value of enforcement.

Figure 1 is a schematic that illustrates the logic used to form expectations for the collective outcome when the enforcement factors are in conflict. ${ }^{5}$ As shown in the figure, ability and willingness on their own have opposing implications for economic cooperation. At different levels of cohesion, net enforcement is constrained by the lesser of either ability or willingness, resulting in an upper bound for net enforcement on average.

This produces an interesting implication for the relationship between structural cohesion and a group's overall economic cooperation. At low levels of cohesion, the limiting enforcement factor will be low ability. At high

\footnotetext{
${ }^{5}$ The schematic includes linear simplifications to illustrate the basic relationships. We fit more nuanced functions to the empirical data in the statistical analysis section.
} 
American Journal of Sociology

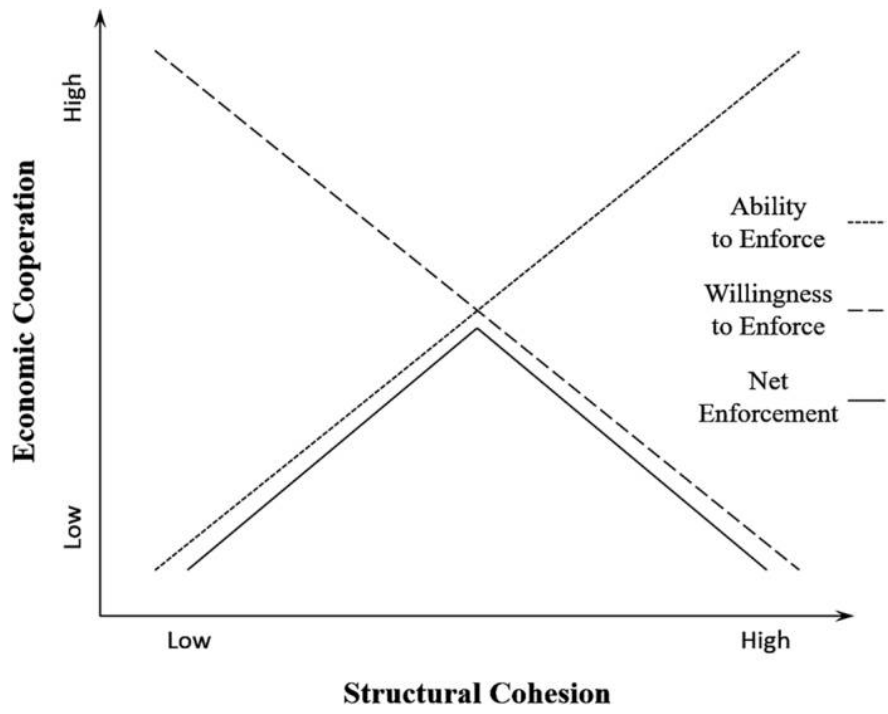

FIG. 1.-Hypothesized effect of net enforcement constrained by ability and willingness. Simplified, linear relationships derived from the literature reviewed in this article. Dotted line, proposed relationship between structural cohesion and economic cooperation if ability to enforce is the only enforcement factor (see proposition 1a). Dashed line, proposed relationship if willingness to enforce is the only enforcement factor (see proposition 1b). Solid line, hypothesized relationship if both enforcement factors are included (i.e., net enforcement). The lesser of the two factors determines the upper bound of net enforcement on average (see hypothesis 1). Color version available as an online enhancement.

levels of cohesion, the limiting enforcement factor will be low willingness. At moderate levels of cohesion, we can theorize a point at which ability and willingness intersect. Here, the role of net enforcement will be greatest when the joint upper bound of both factors is maximal.

This suggests that if propositions $1 \mathrm{a}$ and $1 \mathrm{~b}$ are applicable in a given context, the average relationship between structural cohesion and economic cooperation will be concave downward. ${ }^{6}$ Building on propositions 1a and 1b, we formalize the combined effect as a hypothesis for empirical validation.

Нуротнеsis 1.-An increase in a group's structural cohesion improves its economic cooperation up to a certain threshold through increased ability to enforce compliance; beyond the threshold, an increase in cohesion reduces economic cooperation through decreased willingness to enforce compliance.

Note that this theoretical argument does not suggest that highly cohesive groups are categorically restricted to poor performance. Empirical evidence has documented that such groups at times excel (e.g., Zhao 1998; Chwe

\footnotetext{
${ }^{6}$ Note that in contexts in which observations of structural cohesion are truncated, one may expect a positive or negative linear relationship depending on the range of cohesion observed.
} 
1999). The underlying relationships outlined in propositions $1 \mathrm{a}$ and $1 \mathrm{~b}$ correspond to mean propensities rather than hard upper bounds. Although each group member chooses whether to contribute and whether to enforce, the social structure produces predictable tendencies. In the context of microfinance, this suggests that once structural cohesion surpasses a threshold, the value of social collateral as security against default reverses and declines.

\section{Disconnected Subgroups and Compliance Enforcement}

Group cohesion receives much attention in collective action research. From a different perspective, if we turn to research based on social network analysis and the related literature on community detection in the emerging interdisciplinary field of network science (White, Boorman, and Breiger 1976; Girvan and Newman 2002), we find a breadth of ways to meaningfully characterize group structure. Do other measures of social structure also relate to the tension between ability and willingness to enforce cooperation? In this section, we theorize that by examining the effect of an additional measure of group structure, again in light of a group's ability and willingness to enforce, we can better explain the group's collective outcome.

We specifically consider a feature of a group's substructure that has been found to play a key role in collective action: the existence of disconnected subgroups (Kim and Bearman 1997; Frank and Yasumoto 1998; Macy et al. 2003). The mesolevel concept of the cohesive subgroup has motivated significant research, particularly in terms of how such cohesive subgroups form (Heider 1946; Cartwright and Harary 1956; Feld 1981) and how they can be structurally defined and detected (Burt 1978; Girvan and Newman 2002; Bansal, Bhowmick, and Paymal 2011). Although there are numerous ways in the literature to formally conceptualize the idea of cohesive subgroups, the intuition can generally be characterized as subsets of actors in a population that have substantially greater connection density within the subset than across subsets (Festinger et al. 1950; Wasserman and Faust 1994; Frank and Yasumoto 1998). ${ }^{7}$

How does the existence of disconnected subgroups affect the ability to enforce cooperation? Several scholars have noted that the relationship between group substructure and collective outcomes may engage potentially counteracting mechanisms (Gould 1993; Heckathorn 1993). A collective with cohesive subgroups is vulnerable to cleavage formation (Heckathorn 1993; Moody and White 2003; Friedkin 2004), which affects the opportunities and effectiveness of social sanctions. To focus the scope at this point, we

\footnotetext{
${ }^{7}$ Moody and White (2003) note two types of cohesive subgroups: (1) side-by-side subgroups and (2) hierarchically nested subgroups, e.g., core and periphery. In this study, we focus on the social implications of the former structure.
} 
concentrate on the change in behavior across subgroups. The ability to effectively enforce sanctions across subgroups has been found to be weaker, potentially because one values the sanction or rebuke of a direct connection more heavily (Frank and Yasumoto 1998; Kitts 2006). A significant body of research has also recognized that disconnected subgroups are less likely to communicate regularly and share information, even if the information that is then shared may hold greater novelty or value (Granovetter 1973; Burt 2005). Decreased awareness of actor behavior in the case of infrequent interactions also decreases the value of indirect reciprocity (Nowak and Sigmund 1998) and the value of sanction-based enforceable trust (Portes and Sensenbrenner 1993). In sum, prior research has predominately found that when collectives exhibit disconnected subgroups, several mechanisms related to the ability to enforce compliance are weakened.

We follow the same hypothesis development approach used previously to first clarify the underlying propositions regarding ability and willingness separately, before considering the combined effect. Drawing on existing theory and empirical evidence, we articulate the following proposition.

Proposition 2a.-The existence of disconnected subgroups decreases the ability to enforce compliance on out-subgroup members, ceteris paribus.

While disconnected subgroups may decrease the ability to enforce cooperative behavior, evidence suggests that subgroups exhibit a counterforce: an increased willingness to punish defectors. Social cognition theory suggests that groups at any level may exhibit in-group identification, developing a deindividuated state of identity, often with comparatively negative views of out-groups (Tajfel 1981; Hogg 1992). The development of an in-groupout-group bias can arise from relatively arbitrary categorizations (Berkowitz 1968; Brewer 1979) and can produce potentially antagonistic factions without the knowledge or intent of the actors (Macy et al. 2003). Observational and experimental evidence has shown that such information affects enforcement behavior, so that actors are more likely to punish members of a perceived out-group and more leniency is granted to defectors of the ingroup (Frank and Yasumoto 1998; Chen and Li 2009). ${ }^{8}$ In a similar vein, Desmond (2012) notes that actors may be more likely to enforce on acquaintances rather than strong relations because the tie is viewed as "disposable" and more easily replaced.

This substantial willingness to punish out-group members can be formalized in terms of behavior between structural subgroups.

\footnotetext{
${ }^{8}$ Another factor affecting the willingness to punish out-group norm violators is whether the harmful consequences flow to the in-group or are restricted to the out-group. For example, if the victim is perceived as belonging to the same group as the potential enforcer, the out-group norm violator will be punished more harshly (Bernhard, Fehr, and Fischbacher 2006). In this context, the harm of loan default is not restricted to the outsubgroup, supporting the willingness to punish out-subgroup defectors.
} 
Proposition 2b.-The existence of disconnected subgroups increases the willingness to enforce compliance on out-subgroup members, ceteris paribus.

Thus, disconnected subgroups in the context of microcredit should exhibit the following tension. A borrower may be more eager to apply a sanction to a member of an out-subgroup in default. However, the opportunities and effectiveness of the potential sanctions will typically be diminished.

To theorize the net effect of these opposing forces, we make the same key assumption discussed previously. The role of compliance enforcement will be limited by the lesser of ability or willingness to enforce compliance, all else being equal. We proceed by introducing the effect of disconnected subgroups on an otherwise average group (i.e., moderate cohesion), not at the extremes of either ability or willingness to enforce. For such a group, ability and willingness would be at similar levels. The disconnect will then result in a reduction in ability and an increase in willingness. In this case, the overall result will be a negative effect on net enforcement. This occurs because the group's ability is now relatively lower than its willingness, and the lesser factor determines net enforcement. This suggests that the additional willingness to punish out-subgroup members will be of little value and that the reduced ability will hamper performance. The following hypothesis will be tested for empirical validation.

Hypothesis 2.-The existence of disconnected subgroups decreases a group's overall economic cooperation as net compliance enforcement will be limited more by the reduced ability to enforce on out-subgroup members than the increased willingness to do so, ceteris paribus.

In the context of microfinance, the effect of disconnected subgroups on social collateral has received little attention. This hypothesis indicates that a disconnected group substructure may fundamentally decrease the value of the group's social collateral overall.

\section{Interaction of Disconnected Subgroups and Overall Cohesion}

A population consisting of structural subgroups could have substantially different levels of overall cohesion. Feld (1981) theorized that the spectrum of connection strength between subgroups is primarily a result of their overlapping social foci. Subgroups may be weakly or moderately connected on the basis of the extent of shared activities, such as workplaces, social clubs, hangouts, and so on. The interaction between overall structural cohesion and disconnected subgroups provides insight to varying levels of intersubgroup cohesion.

Researchers have noted that the interaction effect of overall cohesion and group substructure on cooperation is complex (Heckathorn 1993; Kim and Bearman 1997). To form expectations regarding how this interaction relates to enforcement, we again distinguish the tendencies regarding ability and 
willingness. As a starting point, it is intuitive that weakly connected subgroups, as compared to moderately connected subgroups, are at greater risk of splintering socially into fully demarcated subgroups (Zachary 1977; Macy et al. 2003; Moody and White 2003). Other factors held constant, the disconnect between subgroups is reduced with an increase in overall cohesion and exaggerated with a decrease in overall cohesion, assuming that the change in connections is homogeneously distributed across actors in the collective. ${ }^{9}$ As connections increase across subgroups, the opportunities to enforce rise and carry more social weight. This may be viewed as an extension of the logic in proposition 1a applied to behavior across subgroups.

Proposition 3a.-As a group's overall cohesion increases, the ability to enforce compliance on out-subgroup members increases, ceteris paribus.

Likewise, we expect that overall cohesion moderates enforcement willingness associated with a structural cleavage. Willingness to punish a defector is stronger if the norm violator belongs to an out-group (Chen and $\mathrm{Li}$ 2009). Connections and shared activities between groups often mitigate the severity of the out-group bias (Ashforth and Mael 1989). In addition to psychological factors, a decrease in willingness may be rationally motivated. As overlapping ties between subgroups increase, the expectation for future exchange in other situations should also increase (i.e., punishment becomes more costly; Carpenter 2007). Multiple mechanisms support the following relationship between overall cohesion and disconnected subgroups.

Proposition 3b.-As a group's overall cohesion increases, the willingness to enforce compliance on out-subgroup members decreases, ceteris paribus.

Propositions $3 \mathrm{a}$ and $3 \mathrm{~b}$ can be summarized as overall cohesion attenuates the enforcement differences resulting from disconnected subgroups. In the context of microcredit, as subgroups become more connected through overlapping foci, such as trading in the same market or attending the same religious organization, the risks associated with a full social cleavage decrease.

Our expectations for the net impact of the interaction effect are again based on the assumption that the lesser value of ability or willingness determines the likely role enforcement will have on the collective outcome. Recall that the limiting factor in groups with disconnected subgroups is the decreased ability to punish the out-subgroup (hypothesis 2). Further evidence suggests that overall cohesion is expected to strengthen the ability to sanction across subgroups (proposition 3a). Alleviating the more restricted factor in such groups would have a more positive effect on net enforcement.

\footnotetext{
${ }^{9}$ Taken to the extreme, subgroups that become highly connected are structurally equivalent to highly cohesive groups discussed in hypothesis 1 .
} 
Thus, we expect a positive interaction effect as summarized in the following hypothesis.

НуротHEsIs 3.- Structural cohesion has a positive interaction effect with the presence of disconnected subgroups on a group's overall economic cooperation; increased overall cohesion mitigates the limiting factor of inability to enforce compliance on out-subgroup members, ceteris paribus.

Alternatively stated, if a group exhibits a structural cleavage, lower overall cohesion is likely to exacerbate the enforcement problem between subgroups. This offers a final testable hypothesis regarding how variation in group structure should shape our expectations for the efficacy of social collateral in microfinance.

\section{DATA AND METHODS}

Our analytic strategy involves mixed methods. Poteete, Janssen, and Ostrom (2010) have argued that the greatest advances in our theoretical understanding of collective action have resulted from methodological crossfertilization. The benefits of multimethods have been found both sequentially, strengthening findings across studies, as well as within the same research project (Poteete et al. 2010). The design in this study is nested (Small 2011) with different sized samples including complementary data types from the same population of microcredit borrowers in Sierra Leone. The large- $N$ field samples are quantitative and, as will be discussed shortly, are also nested, which allows us to test for statistically significant effects of structure on collective outcomes. The most granular sample involves ethnographic analysis of borrower behavior to examine the veracity of the proposed social enforcement mechanisms. For the sake of readability, we have structured our account of the research design so that we first discuss the quantitative analysis and then follow with the ethnographic analysis. However, in practice, insights gained by applying mixed methods to different data sources informed each other throughout the development of the study, helping to identify when additional confounding factors should be included in the statistical analysis or which interview topics needed further probing. ${ }^{10}$

All the empirical data involve a microfinance organization that uses a standard credit model based on joint-liability group loans (see Morduch 1999). Borrowers are jointly liable for the loan that they take out, such that if one or more members of the group do not repay, the other members are held financially accountable. This type of lending model is well known for incorporating social collateral (Besley and Coate 1995) and is strongly dependent on the economic cooperation of the group (Anthony 2005).

${ }^{10}$ This research was approved by the Central University Research Ethics Committee at the University of Oxford. 
The organization of interest has been in operation since 2002 and has a client base of over 18,000 borrowers spread through semirural Sierra Leone. Potential clients that are interested in taking out a microfinance loan are instructed by the organization to form a group of potential borrowers, typically five, in order to enter into a joint-liability contract. They are told to select members that they "know and trust" to pay back the loan. This organization does not allow members of the same group to be direct kin (i.e., parents, spouses, or siblings). Each borrower must also have his or her own business, roughly deemed capable by the loan officer of supporting repayment of the loan. As typical of many microfinance lending programs, the majority of clients are women (Morduch 1999). In this data set, $84 \%$ of the borrowers are female.

We restricted our data samples to group loans (i.e., excluding alternative products such as individual or agricultural loans), the city where the microfinance organization is headquartered and focuses its lending activity, and a time window in which the organization's group lending practices had been standardized. ${ }^{11}$ All the loans were intended for investment in individual microbusinesses and were scheduled for monthly repayment over 6-12 months. Members of the same group all received equal loan amounts and the same loan terms. The amount of the group loans ranges from 1.2 to 7.5 million leones (SLL), with each borrower receiving between 300,000 and 1.5 million SLL (approximately US $\$ 70-\mathrm{US} \$ 350$ per borrower at the time of data collection).

\section{STATISTICAL ANALYSIS}

The largest of the three data samples, on which we focus the statistical testing of our hypotheses, consists of 1,884 unique borrowers constituting 406 unique groups. These groups received a total of 741 loans over a five-year period, from 2006 to 2011. During that period 5,487 monthly group repayment transactions were recorded. Table 2 provides a summary of descriptive statistics at the loan level.

\section{Dependent Variables}

We modeled a microcredit group's economic cooperation using loan repayment data. For each group loan, the number of days early or late that each

\footnotetext{
${ }^{11}$ From the outset of the research project, sample criteria were defined for the collection of the GPS data. Focusing on clients located in the main city vs. rural villages served two primary purposes: (1) efficiency of data collection allowed us to maximize our sample size, and (2) the city provides more consistent spatial data (i.e., clients are not separated by rivers, mountains, etc.), which makes the use of spatial proximity a more valid proxy for social proximity. Regarding the time window criteria, pre-2006 the organization had not standardized its group lending practices. The usable data (2006-11) represent the vast majority of the organization's records: $96.1 \%$.
} 
Able but Unwilling to Enforce

TABLE 2

Descriptive Statistics: Microcredit Groups in Sierra Leone, 2006-11

\begin{tabular}{|c|c|c|c|c|}
\hline & Mean & $\mathrm{SD}$ & Min & $\operatorname{Max}$ \\
\hline \multicolumn{5}{|l|}{ Structural embeddedness proxy: } \\
\hline 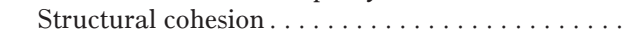 & .00 & 1.00 & -4.25 & 1.05 \\
\hline Disconnected subgroups $(1=$ disconnected $) \ldots \ldots$ & .11 & .31 & .00 & 1.00 \\
\hline \multicolumn{5}{|l|}{ Group characteristic: } \\
\hline Group size. . . . . . . & 4.58 & .49 & 4.00 & 5.00 \\
\hline Proportion female . . . . . . . . . . . . & .84 & .22 & .00 & 1.00 \\
\hline Proportion married $\ldots \ldots \ldots \ldots \ldots \ldots \ldots$ & .93 & .14 & .25 & 1.00 \\
\hline Average number of children. . . . . . . . . . . . & 3.16 & .86 & 1.00 & 6.50 \\
\hline \multicolumn{5}{|l|}{ Financial characteristic: } \\
\hline Average monthly sales $\ldots \ldots \ldots \ldots \ldots \ldots \ldots$ & .82 & .35 & .20 & 4.85 \\
\hline SD monthly sales $\ldots \ldots \ldots \ldots \ldots \ldots \ldots$ & .22 & .41 & .00 & 6.77 \\
\hline Average business equity $\ldots \ldots \ldots \ldots \ldots \ldots$ & .95 & .38 & .24 & 3.98 \\
\hline Proportion petty traders $\ldots \ldots \ldots \ldots \ldots \ldots$ & .64 & .29 & .00 & 1.00 \\
\hline Business type diversity $\ldots \ldots \ldots \ldots \ldots \ldots \ldots$ & .00 & 1.00 & -1.50 & 3.12 \\
\hline \multicolumn{5}{|l|}{ Loan characteristic: } \\
\hline Group loan amount $\ldots \ldots \ldots \ldots \ldots \ldots$ & 2.43 & 1.14 & 1.20 & 7.50 \\
\hline Loan cycle . . . . . . . . . . . . . . . & 2.14 & 1.43 & 1.00 & 9.00 \\
\hline Loan officer $1 \ldots \ldots \ldots \ldots \ldots \ldots \ldots$ & .05 & .22 & .00 & 1.00 \\
\hline Loan officer $2 \ldots \ldots \ldots \ldots \ldots \ldots \ldots$ & .01 & .12 & .00 & 1.00 \\
\hline Loan officer $3 \ldots \ldots \ldots \ldots \ldots \ldots \ldots$ & .16 & .37 & .00 & 1.00 \\
\hline Loan officer $4 \ldots \ldots \ldots \ldots \ldots \ldots \ldots$ & .21 & .41 & .00 & 1.00 \\
\hline Loan officer 5 & .20 & .40 & .00 & 1.00 \\
\hline Loan officer 6 & .11 & .31 & .00 & 1.00 \\
\hline Loan officer $7 \ldots \ldots \ldots \ldots \ldots \ldots \ldots$ & .07 & .25 & .00 & 1.00 \\
\hline Loan officer $8 \ldots \ldots \ldots \ldots \ldots \ldots \ldots$ & .01 & .09 & .00 & 1.00 \\
\hline \multicolumn{5}{|l|}{ Dependent variable: } \\
\hline Group repayment (days late coded negative). . . . . & -35.08 & 85.58 & -536.0 & 4.00 \\
\hline
\end{tabular}

Note. $-N=741$ loan observations nested in 406 borrowing groups (comprising 1,884 unique members). All descriptive statistics are calculated at the loan level. Financial amounts in millions of leones (SLL). Structural embeddedness proxies are derived from Euclidean minimum spanning trees.

monthly payment was made has been recorded. The detail of the repayment distribution is more fine grained than that used by numerous other studies of microcredit that have focused on the default rate (e.g., Wydick 1999; Paxton et al. 2000). Days early or overdue provide significant insight to group behavior because default is relatively rare (6.2\% of loans in this study). To construct a loan-level cooperation measure, we used the maximum number of days overdue for all the scheduled payments of the loan. ${ }^{12}$ In the core analysis, economic cooperation is treated as a continuous variable. Days early are coded positive and days overdue negative, so that a higher value

${ }^{12}$ The core statistical analyses are focused at the loan level, as there is no recorded variation in the independent and control variables below the loan level. Repayment data below the loan level are used in supporting analyses to examine variation in monthly behavior relevant to financial ability to pay and potential financial confounders. 
of the dependent variable indicates better group repayment. We took various steps to verify that the results are not sensitive to our treatment of the dependent variable. See appendix A for models accounting for skewness and high-influence observations, censored regression models for bounded distributions (values at the extremes of the distribution, i.e., default or prepayment, may not reflect the underlying behavior of interest), and survival analysis across loan cycles (default is treated as a binary event). The results are robust to all the alternative specifications.

We expect that loan repayment is affected by both a group's cooperative efforts as well as its financial ability to pay. In this study, several steps are taken to distinguish the two and confirm that the observed relationships are primarily capturing variation in groups' economic cooperation rather than variation in groups' financial capacity to pay. The supporting analyses that address this issue occur at relevant points throughout the article and appendixes, but here we provide a consolidated overview of the relevant (1) contextual factors, (2) statistical controls, and (3) supplementary quantitative analysis.

First, in the Sierra Leonean context, clients that choose to join a group loan have similar financial backgrounds as a result of the loan-screening process. Each member is required to have her own business, and if a client has a notably stronger financial position, she would typically qualify for a larger individual loan and would not be included in this study. After the loans are disbursed, if the microfinance organization deems that a group as a whole has encountered an event that prevents it from repaying, for example, if the members' business stalls were colocated and damaged in a fire, the organization will reschedule the loan. In addition, the microfinance organization requires that $10 \%$ of each loan is immediately placed into a group deposit account. If the group is financially unable to make a payment, members have the option of using this account to cover the missing payment. However, this option is rarely used by overdue groups, suggesting a failure of group cooperation rather than financial inability to repay.

Second, substantial statistical controls are included in the model to account for financial variation resulting from both individual and group factors. We include controls for personal characteristics that may affect one's ability to pay, such as marital status and number of dependents in the household, as well as variables directly related to income, such as a client's business type, business equity, and monthly sales. To account for the potential correlation of income streams within a group, we also control for business type diversity or lack thereof. See the section on control variables for more detail, as well as appendix B on spatial autocorrelation of economic performance.

Third, in the supplementary analysis we exploit an additional level of detail in the financial records to further distinguish the hypothesized cooperative mechanisms from the role of financial ability to repay. A fortunate 
feature of the data set is that it includes records of partial payments for each scheduled monthly repayment. For example, if a group is scheduled to make a monthly payment of 200,000 SLL, but on the due date the group only has 10,000 SLL available, the group may choose to submit this partial amount. We use these subpayment data to construct an alternative measure of economic cooperation that minimizes the role of the group's ability to make a full payment. The statistical models were rerun using this alternative measure and the substantive findings are the same. Appendix C contains the detailed results. The analysis indicates that while groups do vary in their monthly ability to repay, the observed relationships between group structure and cooperation are not driven by variation in financial ability.

\section{Independent Variables}

Our hypotheses involve two measures of a group's structural embeddedness: (1) average structural cohesion and (2) the existence of disconnected subgroups. In the largest data sample, we propose using fine-grained spatial structures of the groups as reasonable proxies for these measures of structural embeddedness. We motivate this approach with extensive previous research and validate the method using a nested subset of quantified social affiliation data from the same microcredit borrowers in Sierra Leone.

Numerous scholars have demonstrated a systematic relationship between spatial propinquity and social proximity (Bossard 1932; Zipf 1949; Blau 1977; Latané et al. 1995). The relationship has been found to be robust across varying distances and contexts (Hare and Bales 1963; Leskovec and Horvitz 2007; Rivera, Soderstrom, and Uzzi 2010). The consistency of the correlation results from underlying sociospatial mechanisms. Spatial structure can be summarized as shaping social interaction in two fundamental ways: (1) through the likelihood of tie formation and (2) by influencing the nature of ongoing interaction (Festinger et al. 1950; Feld 1981).

Feld's (1981) theory on the focused organization of social ties notes how physical entities, such as workplaces, hangouts, and religious organizations, often serve as foci that shape a community's overall social structure. Physical distance plays a key role in tie formation by increasing the likelihood of passive contact, for example, a chance encounter walking by a neighbor's door (Festinger et al. 1950). Post tie formation, spatial proximity influences the frequency of interaction and information exchange (Caplow and Forman 1950), as well as the effort required to maintain a relationship (Martin and Yeung 2006). ${ }^{13}$

\footnotetext{
${ }^{13}$ Appendix D addresses concerns regarding the effects of communication and transport technology on the relationship between spatial and social proximity.
} 
We found substantial support for this theoretical argument in our own ethnographic fieldwork in Sierra Leone. When microfinance clients were asked open-ended questions regarding how they knew other group members, they frequently responded with social connections resulting from spatial proximity. Varied descriptions included personal relationships based on living in the same neighborhood ("We grew up right next to each other," "I babysit for her," "We eat rice together and laugh"), connections through religious or community organizations ("We are all Christians and go to the same church nearby," "We see each other every day in the Mosque," "We used to do Osusu [community savings group]"), and business-associated relationships ("My colleagues [group members] work in the same market, the Big Market," "She always pays a visit to me and I give her [financial] advice”).

To serve as an effective proxy, high-resolution spatial data were needed. In this data set, all the borrowers live in a single city in Sierra Leone with a population of roughly 100,000 residents spread over 16 square kilometers. GPS coordinates for residential addresses registered with the microfinance institution were collected by the authors using a Trimble Juno SC unit with ArcGIS software. See figure 2 for a map of the distribution of clients.

The high-resolution GPS data capture continuous measures between all clients rather than aggregated block areas. Other researchers have demonstrated the value of incorporating such advances in geographic technology to enhance the value of spatial data in sociological analysis (Downey 2006; Yenkey 2015). We were able to collect spatial data on $95.2 \%$ of the borrowers. The unknown spatial data were primarily due to human error during the original recording of borrowers' addresses; we consider the $4.8 \%$ of the missing spatial data to be at random. ${ }^{14}$

Structural cohesion.-Groups with greater structural cohesion are often characterized as having a greater number of redundant ties (Coleman 1988) or a greater multiplicity of tie types between actors (Uzzi 1999). We construct a proxy for structural cohesion based on the assumption that microfinance clients in Sierra Leone who live near each other are likely to have a greater number of such ties. However, our approach here is conservative, and we first examine the veracity of this assumption empirically.

We surveyed a subset of 410 microfinance clients in Sierra Leone regarding their social affiliations. The subset included all the microcredit clients receiving a loan from the lending institution over the first six months of 2011. Complete survey data were collected on 378 of the 410 clients receiving a disbursement $(92.2 \%)$. Clients were asked to list their social affiliations

\footnotetext{
${ }^{14}$ The researchers verified the self-reported residential addresses of a random sample of over 60 clients. No cases of deception were found, suggesting false addresses are not common in this data set.
} 


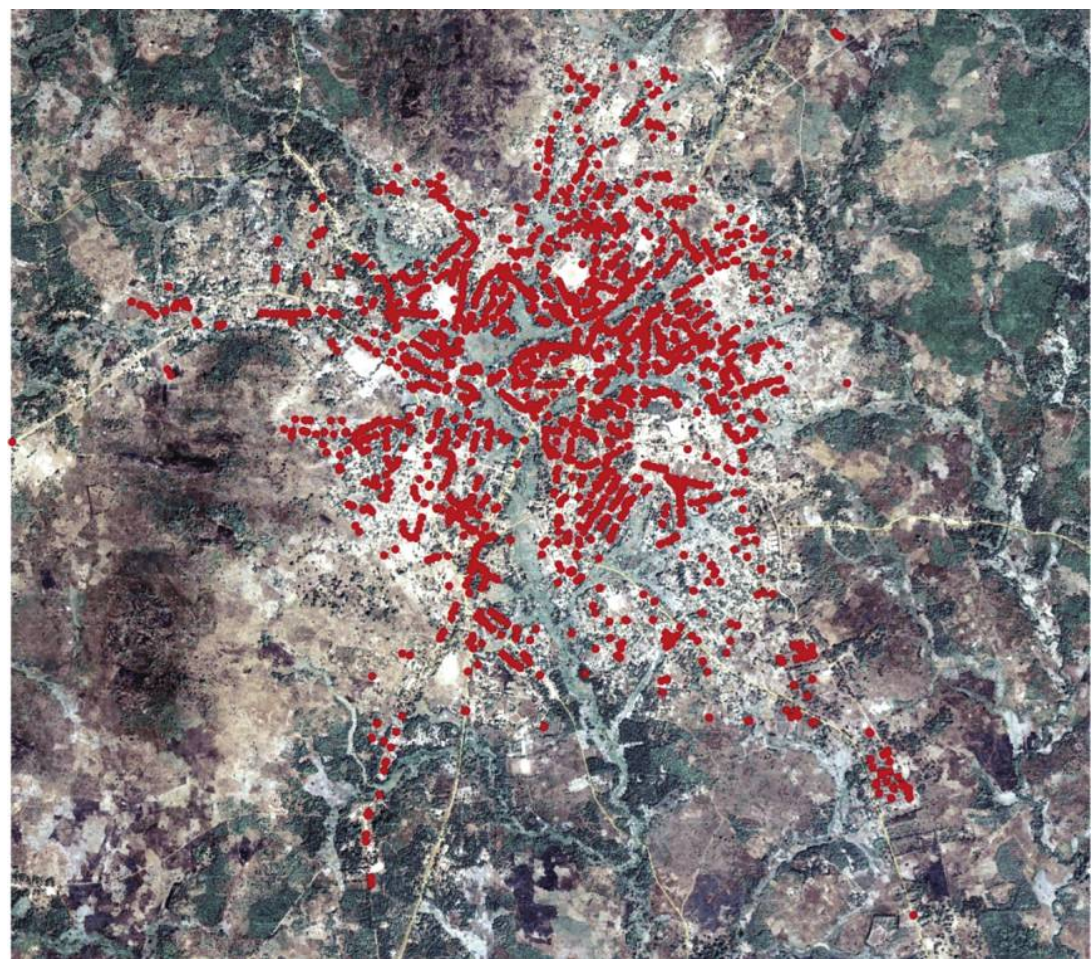

FIG. 2.-Spatial distribution of microcredit clients in Sierra Leone, 2006-11. $N=1,884$ residential coordinates. Data gathered by GPS in city of study, Sierra Leone.

in terms of (1) religious organization; (2) place of business; (3) educational organization; (4) Osusu, informal savings group (see Geertz 1962); and (5) ethnic tribe. Clients were instructed only to report affiliations in which they had been active in the prior six months (referring to affiliations 1-4). Table 3 provides a summary of the social affiliation data.

It is a common methodological approach in social network analysis to use shared social affiliations to infer likely direct connections, by formally converting a two-mode network into a one-mode network (Wasserman and Faust 1994). Figure 3 provides a visualization of the data in the format of a projected one-mode network. A tie represents a shared social affiliation. ${ }^{15}$

We examined the relationship between spatial proximity and the probability of a multiplex tie between any two clients. A multiplex tie was operationalized as having two or more social affiliations in common (religious organization,

${ }^{15}$ We do not use ethnic tribe as a social affiliation in this analysis. With $72.5 \%$ of the respondents belonging to the largest tribe (Temne), it does not represent a meaningful social affiliation. Instead, it is used in the analysis as a control variable. 
TABLE 3

Summary of Social Affiliation Survey: Microcredit Clients in Sierra Leone, 2011

\begin{tabular}{lccccc}
\hline \hline & \multicolumn{5}{c}{ Social Focus } \\
\cline { 2 - 6 } & $\begin{array}{c}\text { Religious } \\
\text { Organization }\end{array}$ & $\begin{array}{c}\text { Place of } \\
\text { Business }\end{array}$ & $\begin{array}{c}\text { Educational } \\
\text { Organization }\end{array}$ & $\begin{array}{c}\text { Informal } \\
\text { Lending Group }\end{array}$ & Tribe \\
\hline Surveyed clients . . . . . . . & 410 & 410 & 410 & 410 & 410 \\
Completed surveys . . . . & 378 & 378 & 378 & 378 & 378 \\
Reported affiliations . . . & 355 & 310 & 153 & 198 & 372 \\
Reported distinct foci . . . & 82 & 127 & 43 & 136 & 13 \\
Mean affiliation/focus . . . & 4.3 & 2.4 & 3.6 & 1.5 & 28.6 \\
SD affiliation/focus . . . . . & 5.5 & 4.2 & 3.5 & .8 & 74.3 \\
Min affiliation/focus ..... & 1 & 1 & 1 & 1 & 1 \\
Max affiliation/focus. . . . & 34 & 33 & 13 & 5 & 274 \\
\hline
\end{tabular}

place of business, educational organization, or informal lending group) ${ }^{16} \mathrm{We}$ fitted a binary logistic regression model to the likelihood of a multiplex tie. Such a connection is possible between any two members of the 378 survey respondents, producing a potential 71,253 ties. The model included controls for individual attributes that may affect the probability of a tie: tribe, gender, marital status, group leader status, business type, business strength, number of children, and number of additional dependents.

Table 4 provides the results of the regression. Model 1 provides a baseline control model. Referring to model 2, the coefficient of spatial distance is negative and significant with $P<.001$. As spatial distance increases, the likelihood of a multiplex social tie decreases significantly. The nature of the relationship is as hypothesized and also exhibits a relatively low level of noise. Figure 4 displays how rapidly the probability decays with distance. The figure displays both the functional form fit by the regression model and the empirical deviation around the functional form. The analysis provides further empirical support that a group's spatial structure in this context may serve as an effective proxy for its structural cohesion.

To quantify a group's spatial structure we use the Euclidian minimum spanning tree (EMST) based on borrowers' residential addresses. The EMST calculates the shortest overall distance to connect a group's set of geographical points (see Eppstein 2000). The value between each pair of points is the Euclidian distance. See figure 5 for EMST examples of empirical microcredit groups.

We considered alternative approaches for calculating a group's spatial structure but found the EMST to be both parsimonious and appropriate

\footnotetext{
${ }^{16}$ We examined the likelihood of a multiplex tie rather than a single affiliation, as it serves as a stronger measure of structural embeddedness. Single affiliations to such groups may represent a relatively weak tie (Feld 1981).
} 
Able but Unwilling to Enforce

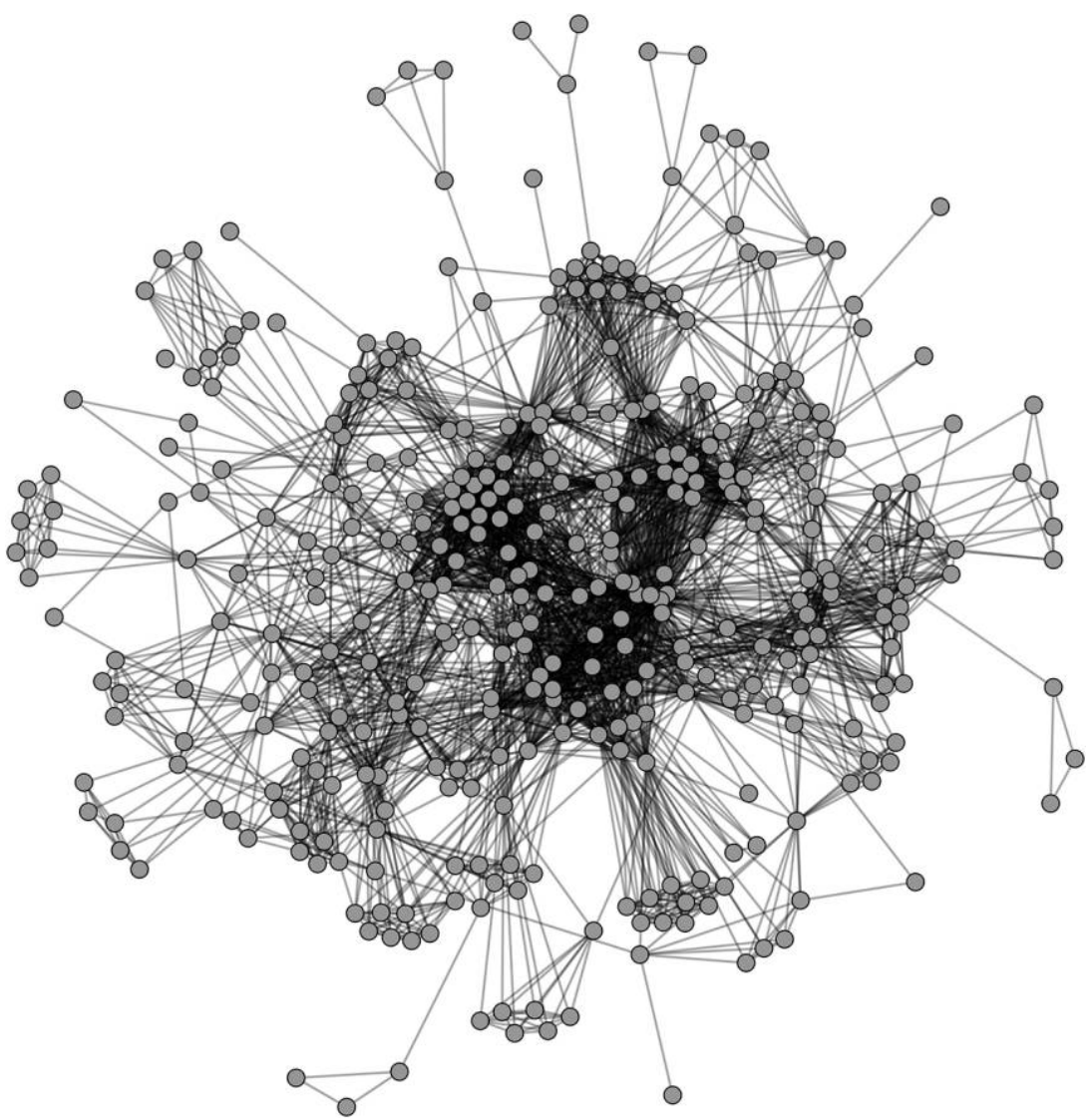

FIG. 3.-Social affiliation network: microcredit clients in Sierra Leone, 2011. $N=378$ microcredit clients (subset surveyed for social affiliations; 13 isolates not displayed). Incidence matrix of affiliations converted to one-mode network. Layout algorithm is Fruchterman Reingold. Network density $=0.048$. Average path length $=3.1$. See table 3 for detail on social affiliation types: religious organization, place of business, educational organization, informal lending group. Color version available online.

for the context. The average group EMST was 1.06 kilometers, with a range from 0 meters (although it is rare in the data set, it reflects groups that are residentially colocated) to 5.24 kilometers. ${ }^{17}$ As stated previously, the policy of the microfinance institution does not allow direct kin to be members of the same group. The average EMST branch length was 299 meters. To

${ }^{17}$ It is possible that clients with the same residential address (i.e., a spatial distance of 0 ) represent a categorically different type of social relationship. We explored this by including a binary variable in our analysis $(1=$ colocation $)$ and found that it had no effect. 
TABLE 4

Binary Logistic Regression Predicting the Effect of Spatial Proximity on Multiplex Social Tie Probability in Sierra Leone, 2011

\begin{tabular}{|c|c|c|c|c|}
\hline & \multicolumn{2}{|c|}{ Model 1} & \multicolumn{2}{|c|}{ Model 2} \\
\hline & Coefficient & $\mathrm{SE}$ & Coefficient & SE \\
\hline Spatial distance. . . . . . . . . & $\ldots$ & . . & $-2.72 * * *$ & .16 \\
\hline Tribe $(1=$ match $) \ldots \ldots \ldots \ldots$ & $.42 * * *$ & .12 & $.26 *$ & .13 \\
\hline Gender $(1=$ match $) \ldots \ldots \ldots$ & $.45^{*}$ & .18 & $.38 *$ & .19 \\
\hline Marital status $(1=$ match $) \ldots \ldots$ & $.60 * *$ & .21 & $.54 *$ & .24 \\
\hline Group leader $(1=$ match $) \ldots \ldots$ & $-.33 * *$ & .12 & $-.29 *$ & .13 \\
\hline Business type $(1=$ match $) \ldots \ldots$ & $.38 * *$ & .12 & $.44 * * *$ & .13 \\
\hline Monthly sales difference. . . . . . . . & $-.73 * * *$ & .17 & $-.57 * *$ & .18 \\
\hline Number children difference ...... & $-.19 * * *$ & .05 & $-.14 * *$ & .05 \\
\hline Number dependents difference ... & -.10 & .06 & -.10 & .07 \\
\hline Constant . . . . . . . . . . & $-6.14 * * *$ & .30 & $-3.75 * * *$ & .33 \\
\hline Deviance ............... & $3,819.0$ & & $2,837.4$ & \\
\hline
\end{tabular}

Note. $-N=71,253$ potential ties. Distance in kilometers; financial amounts in millions of leones (SLL). Two-tailed significance tests.

$$
\begin{aligned}
& * P<.05 . \\
& * * P<.01 . \\
& * * * P<.001 .
\end{aligned}
$$

put the distances in context, the city is roughly 4 kilometers in diameter. The structural cohesion proxy was constructed by using a group's average EMST branch length and reversing the sign so that a positive value signifies cohesion rather than dispersion. The variable was mean centered with a standard deviation of 1 .

Disconnected subgroups.-We follow a similar procedure for quantifying the second feature of a group's structural embeddedness: the existence of disconnected subgroups. This has been characterized structurally as having subsets of actors who have greater connection density within the subset than across subsets (Festinger et al. 1950; Frank and Yasumoto 1998). Again, we use spatial structure as a proxy and assume that subgroups that are spatially distant are more likely to be socially disconnected. We have already examined social affiliation data and found that spatial proximity between individual clients is negatively correlated with the probability of a multiplex tie. However, it is useful to further probe our construct validity by empirically questioning whether an increase in physical distance from a spatial subgroup exhibits a systematic relationship with the likelihood of being socially disconnected from that subgroup.

We test the assumption by using the same social affiliation data with the subset of 378 clients discussed previously. To define a clear subgroup, we used a standard approach for distinguishing the main component of the social network (Wasserman and Faust 1994). We then fitted a binary logistic 
Able but Unwilling to Enforce

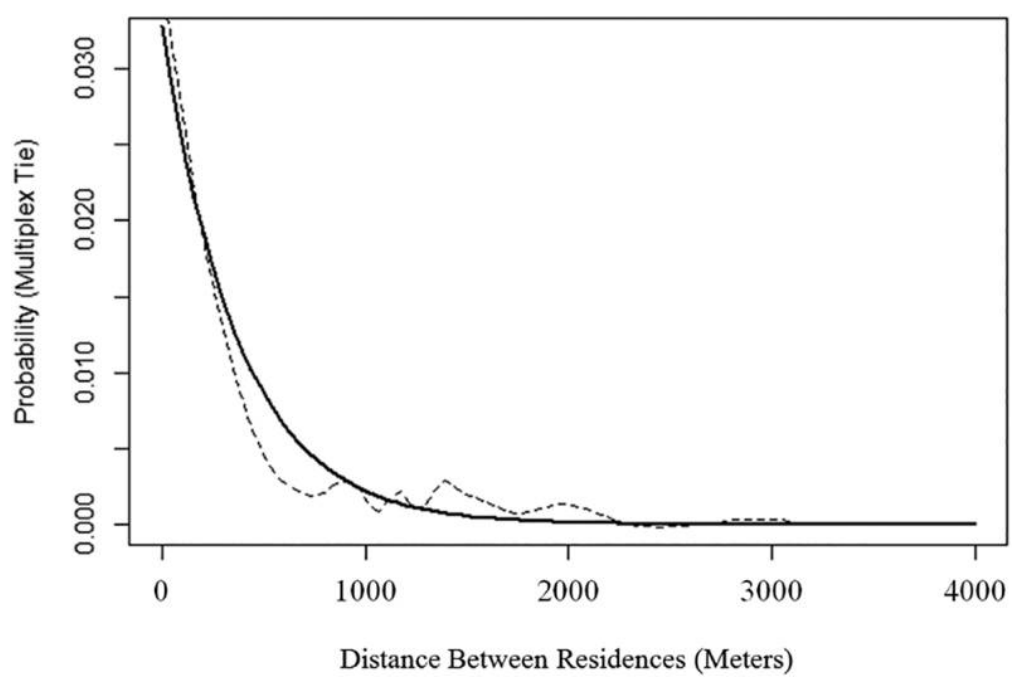

FIG. 4.-Multiplex social tie probability spline: microcredit clients in Sierra Leone, 2011. $N=71,253$ potential ties (378 clients). Solid line, implied relationship of the functional form produced by logistic regression, holding other variables at their means (see table 4); dotted line, 20-piece spline of the empirical likelihood of a multiplex social tie.

regression model to the likelihood of being disconnected from the main social component. Table 5 summarizes the regression results for models without and with spatial proximity. We found that as the physical distance to the nearest member of the main component increases, the probability of being socially disconnected from the component also increases as expected. The coefficient of spatial distance is positive and significant with $P<.001$. Figure 6 displays both the functional form fit by the regression model and the empirical deviation around the functional form. The analysis indicates that spatially distant subgroups may effectively function as a proxy for socially disconnected subgroups.

We defined the proxy for groups consisting of socially disconnected subgroups as a binary variable with 1 representing groups consisting of spatially fragmented subgroups; 0 otherwise. A spatial subgroup was defined as two or more borrowers living within less than 100 meters of each other. Subgroups were considered to be spatially fragmented if there was a distance of more than 100 meters between their nearest members. One would expect that the relevant threshold distance for defining a subgroup is context dependent. Our use of 100 meters was derived from the fieldwork in Sierra Leone as a critical distance for frequent interaction. For individuals living less than 100 meters apart, there is substantial social interaction on a daily basis that occurs unintentionally (i.e., without prior planning). Such situations are known to correlate with tie formation and ongoing interaction (Festinger et al. 1950; 
American Journal of Sociology

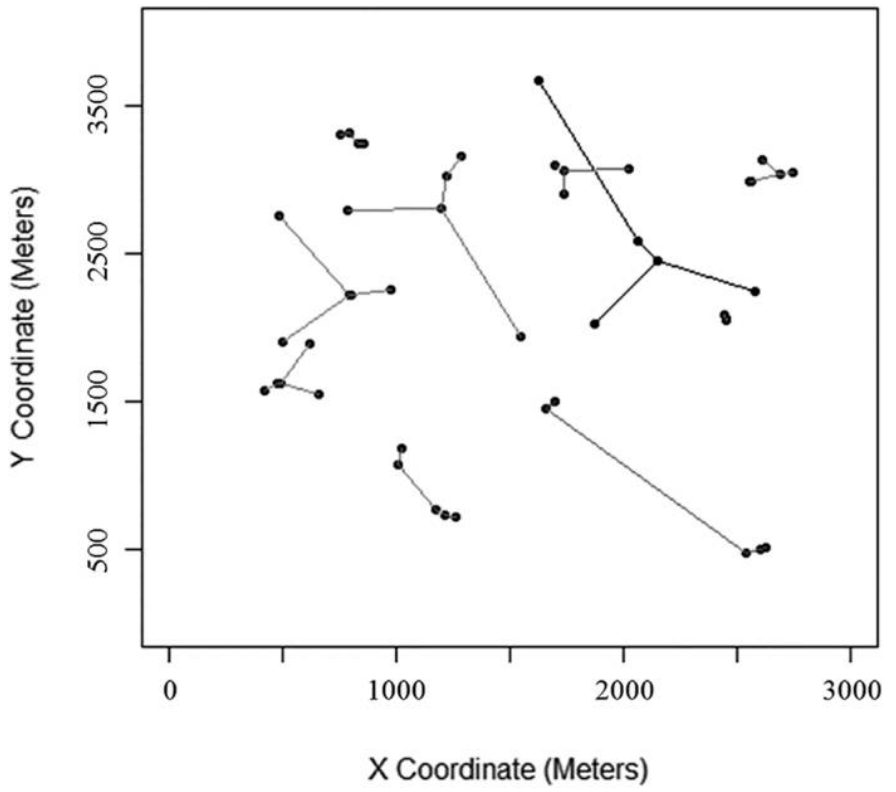

FIG. 5.-Euclidian minimum spanning trees: 10 microcredit groups in Sierra Leone, 2006-11, illustrating the heterogeneity of spatial configurations from the empirical city of study. Full data set: 1,884 borrowers constituting 406 EMSTs. Color version available online.

Feld 1981). Furthermore, we examined the robustness of the results to different values of the distance threshold, ranging from 50 to 200 meters. In appendix E, data on alternative cutoff points are presented. The results are robust to variation in the distance threshold; disconnected subgroups based on alternative cutoff points produce the same substantive effect on a group's cooperative outcome.

\section{Control Variables}

Having defined the dependent and independent variables of interest, the next primary concern is dealing with potential unobserved confounders, that is, in this case, factors correlated with group structure that may affect repayment behavior. If unaccounted for, their role could be misinterpreted as resulting from the hypothesized variables (Hill, Griffiths, and Lim 2018). In this context, there are three primary categories of potential confounders that should be considered: (1) individual characteristics, (2) financial factors, and (3) organizational or loan-specific factors.

Individual characteristics may influence social dynamics of the group, as well as individual propensities to repay. For example, substantial research 
TABLE 5

Binary Logistic Regression Predicting the Effect of Spatial Proximity on Disconnect from Main Social Component: Sierra Leone, 2011

\begin{tabular}{|c|c|c|c|c|}
\hline & \multicolumn{2}{|c|}{ Model 1} & \multicolumn{2}{|c|}{ Model 2} \\
\hline & Coefficient & $\mathrm{SE}$ & Coefficient & $\mathrm{SE}$ \\
\hline Spatial distance. . . . . . . . . . . . & $\ldots$ & $\ldots$ & $.01 * * *$ & .00 \\
\hline Tribe $(1=$ Temne $) \ldots \ldots \ldots \ldots$ & .05 & .37 & .07 & .41 \\
\hline Gender $(1=$ female $) \ldots \ldots \ldots \ldots$ & -.16 & .57 & .23 & .62 \\
\hline Marital status $(1=$ married $) \ldots \ldots$ & .16 & .58 & .52 & .68 \\
\hline Group leader $(1=$ leader $) \ldots \ldots \ldots$ & -.07 & .40 & -.17 & .43 \\
\hline Business type $(1=$ petty trading $) ..$ & -.30 & .37 & -.55 & .40 \\
\hline Monthly sales $\ldots \ldots \ldots \ldots \ldots \ldots$ & .32 & .42 & .38 & .45 \\
\hline Number of children $\ldots \ldots \ldots \ldots \ldots$ & .09 & .12 & .04 & .14 \\
\hline Number of dependents . . . . . . . . . & .25 & .26 & .06 & .30 \\
\hline Constant $\ldots \ldots \ldots \ldots \ldots \ldots$ & 1.57 & .96 & -.30 & 1.08 \\
\hline Deviance ............... & 260.49 & & 202.14 & \\
\hline
\end{tabular}

Note. $-N=378$ clients. Distance in kilometers; financial amounts in millions of leones (SLL). Two-tailed significance tests.

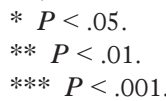

has indicated that the gender of clients is related to microcredit repayment. Studies have found higher repayment from female microcredit clients (e.g., Khandker, Khalily, and Khan 1995), linked to mechanisms based on responsiveness to social pressure, reduced mobility (potentially related to children), and more responsible use of funds (Kevane and Wydick 2001; Armendáriz and Morduch 2010). Anthony and Horne (2003) suggest that higher repayment in groups with a greater proportion of women is a result of social expectations for cooperation rather than inherent gender differences. We used the individual characteristics to construct group-level controls, appropriate to the level of the regression analysis. Resulting group composition controls include proportion female, proportion married, and average number of children. ${ }^{18}$

Second, we took several steps to ensure that a group's spatial structure is not confounded with financial factors affecting the ability to repay the loan. In this context, the primary source of income for clients results from their

${ }^{18}$ The level of educational attainment could also affect repayment behavior, particularly regarding a client's financial ability to contribute to loan repayment. However, microfinance staff emphasized reliability problems with such data in this context. The selfselection process of individuals interested in microcredit naturally reduces the variation in education levels, and social desirability bias compounds the problem, i.e., potential clients are likely to misrepresent their educational level, thinking that it affects the loan approval process. We prefer to use measures related to a client's business as a more direct measure of his or her financial ability to repay. 
American Journal of Sociology

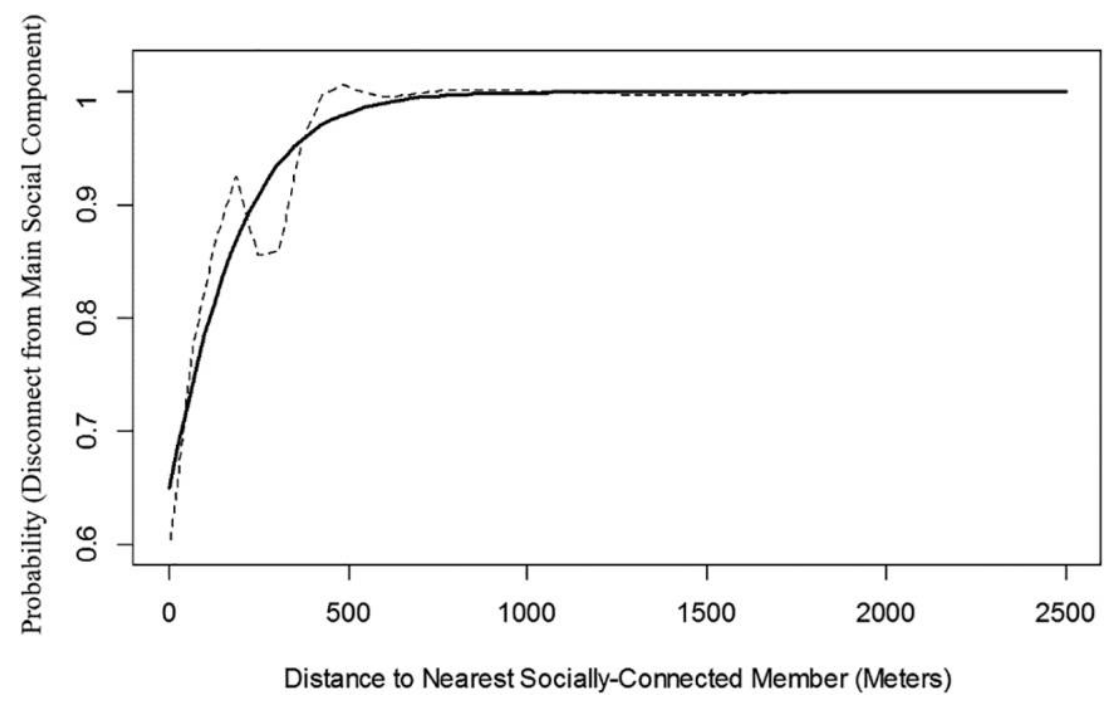

FIG. 6.-Disconnect from main social component probability spline: microcredit clients in Sierra Leone, 2011. $N=378$ clients. Solid line, implied relationship of the functional form produced by logistic regression, holding other variables at their means (see table 5); dashed line, 10-piece spline of the empirical likelihood of a client disconnected from the main social component of the affiliation network.

microbusinesses. To control for client variation in their ability to pay, we considered monthly sales and business equity. As with the social controls, we constructed group-level variables from the individual characteristics. ${ }^{19}$ In addition to average monthly sales and average business equity for each group, we also included standard deviation in monthly sales to control for the possibility that within-group differences in financial strength affect cooperative behavior.

Another concern is that the ability to pay may be affected by clients' type of business, for example, affecting the seasonality of their income or its correlation with the incomes of other group members. To account for this, we include control variables concerning business types. Using information gathered by the loan officer, each borrower's business was categorized into one of six types: food, clothing, service, petty trading, single item trading, and other. The predominant business type of borrowers in this data set is petty trading at $64 \%$. Using the business type data, we constructed two grouplevel controls: proportion of petty traders and business type diversity. Proportion of petty traders captured the group's focus on the predominant

${ }^{19}$ Ideally, controls for financial ability to pay would extend beyond the individual's income, e.g., household income. However, in this context, the microfinance institution encourages empowering women and restricts requesting a spouse's income. As such, we use measures related to the client's business as a proxy for financial ability to repay. 
business type. Business type diversity was calculated as the number of different business types within the group, divided by the number of group members. This value was then normalized with a mean of 0 and a standard deviation of 1 . Business type diversity is a particularly important control because one could question whether the effects of structural cohesion are actually driven by correlation of business types (an undiversified portfolio) rather than social mechanisms. ${ }^{20}$

Finally, we considered organizational and loan-specific factors that may affect group repayment. Through interviews with the staff and management of the microfinance institution, we learned of the primary organizational factors that may produce unwanted artifacts in the data. Characteristics of the loan that we controlled for included group size, loan amount, loan officer (dummy variables for nine loan officers), and loan cycle (the loan number taken by the group, e.g., first, second, third). ${ }^{21}$

\section{Statistical Model}

We modeled the effects of structural cohesion and disconnected subgroups on loan repayment using a hierarchical linear model for repeated measures (Snijders and Bosker 2012). As groups may take multiple loans and their performance may not be independent, we included random intercepts for each microcredit group. We estimated a model of the following form:

$$
Y_{i j}=\gamma_{00}+\gamma_{10} x_{1 i j}+\cdots+\gamma_{p 0} x_{p i j}+\gamma_{01} z_{1 j}+\cdots+\gamma_{0 q} z_{q i}+U_{0 j}+R_{i j},
$$

where $Y_{i j}$ denotes days overdue for loan $i$ for microcredit group $j ; \gamma_{00}$ is the intercept; $\gamma_{p 0}$ is the coefficient for the loan-level variables, $x_{p i j} ; \gamma_{0 q}$ is the coefficient for the group-level variables, $z_{q i} ; U_{0 j}$ is the residual at the group level; and $R_{i j}$ is the residual at the loan level (Snijders and Bosker 2012). In the results section, we consider alternative approaches to modeling the data and find the results to be robust.

\section{STATISTICAL RESULTS}

Table 6 summarizes four models testing our hypotheses derived from existing theory on group social structure and economic cooperation. Model 1

\footnotetext{
${ }^{20}$ A lack of business type diversity could have a stronger effect on spatially dense groups, e.g., increasing within-group competition. The core regression models were rerun including an interaction effect between a group's business type diversity and average spatial distance. However, the interaction effect was not significant with $P>.681$.

${ }^{21}$ Additional models were built controlling for exogenous factors using dummy variables for time periods: six month periods based on the primary rainy and dry seasons in Sierra Leone. The substantive results were unchanged.
} 


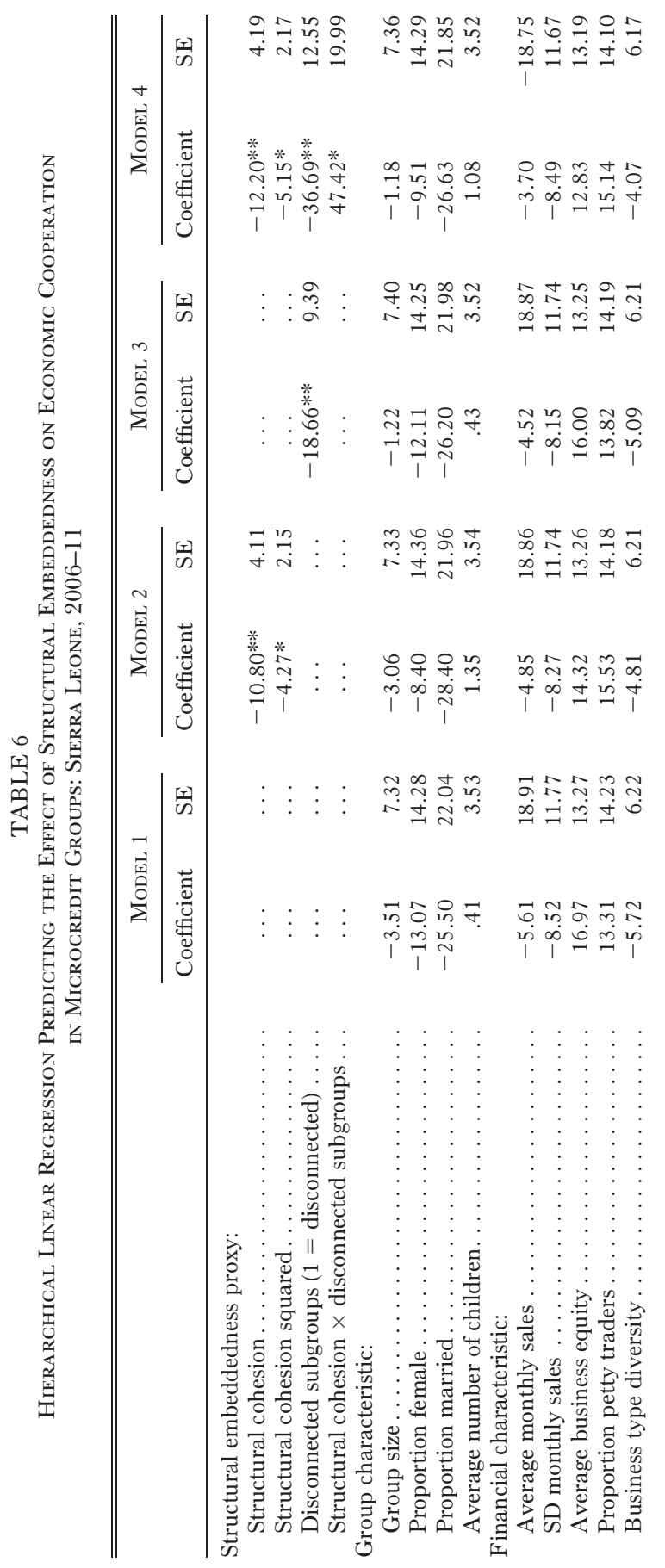




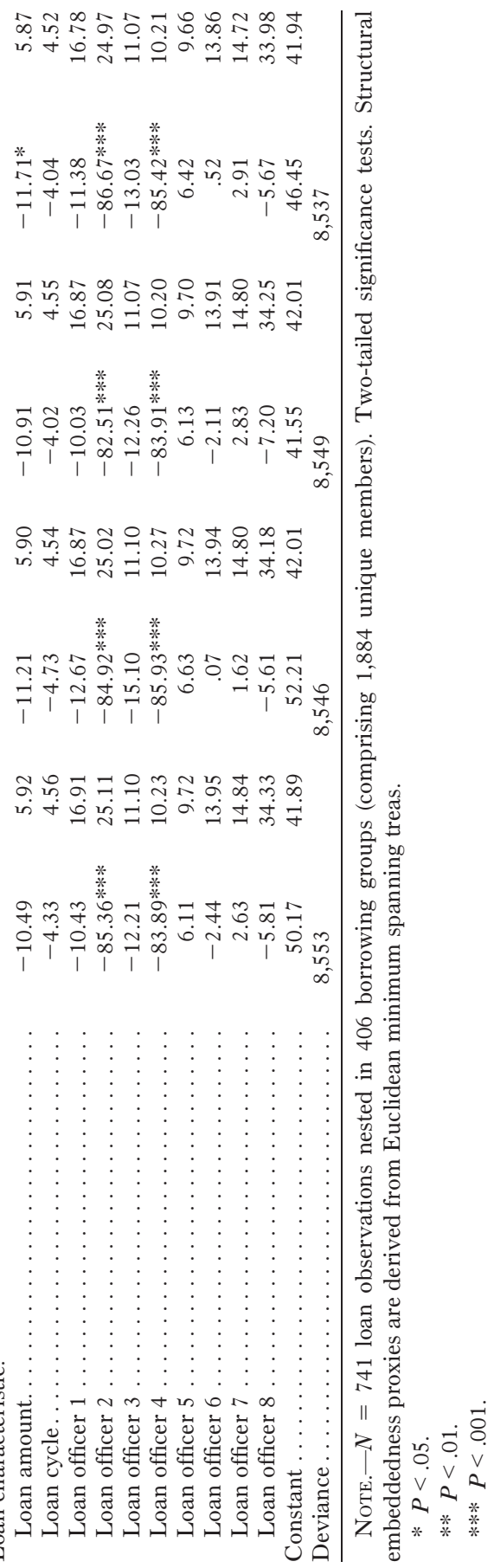


serves as a baseline control model accounting for group composition, financial indicators, and loan characteristics. Model 2 relates to hypothesis 1 regarding the effects of structural cohesion on economic cooperation. Model 3 relates to hypothesis 2, the effect of disconnected subgroups. Model 4, the complete specification, also tests the interaction effect of structural cohesion with the existence of disconnected subgroups, hypothesis 3 .

Model 2 includes variables for a group's structural cohesion and structural cohesion squared. The coefficient of structural cohesion is negative and significant with $P<.01$, indicating that as a group's structural cohesion increases its performance declines (i.e., more days overdue). The coefficient of structural cohesion squared is also negative and significant, with $P<.05$, indicating that the relationship between cohesion and cooperation is nonlinear. The $F$-statistic for improvement in fit over a linear model is significant with $P<.02$. We also validated statistically that a second degree polynomial provides the best fit to the empirical data, testing first-, second-, and thirddegree polynomials. It indicates that groups of moderate structural cohesion perform better than those groups with very high or very low levels of cohesion. The results of model 2 provide support for hypothesis 1.

Model 3 introduces the binary variable for groups with disconnected subgroups. The coefficient is negative and significant with $P<.01$. This provides support for hypothesis 2 that groups consisting of disconnected subgroups perform worse than groups without disconnected subgroups.

Model 4 is the full model including the interaction effect between structural cohesion and disconnected subgroups. The coefficient of the interaction effect is positive and significant with $P<.05$. This indicates that if a group consists of disconnected subgroups, the higher the level of average structural cohesion for the group, the higher the level of economic cooperation. This provides support for hypothesis 3 that overall cohesion mitigates the risk of disconnected subgroups. Moreover, model 4 shows support for all three hypotheses in the full specification.

In addition to the statistical tests, support for the hypotheses can be observed visually. Figure 7 provides a graphical summary of the empirical relationships based on the full statistical model (table 6, model 4). In hypothesis 1 , it was predicted that the relationship between structural cohesion and economic cooperation would be concave downward. The empirical relationship can be observed in the solid curve fitted to the total data set. In hypothesis 2, it was predicted that the average level of cooperation in groups with disconnected subgroups would be lower than those without. The dotted curve in the figure is fitted to groups without disconnected subgroups, and the dashed curve to those with disconnected subgroups. One can observe that the curve for groups with disconnected subgroups is significantly lower on average. In hypothesis 3, a positive interaction effect between structural cohesion and disconnected subgroups was predicted. One can 
Able but Unwilling to Enforce

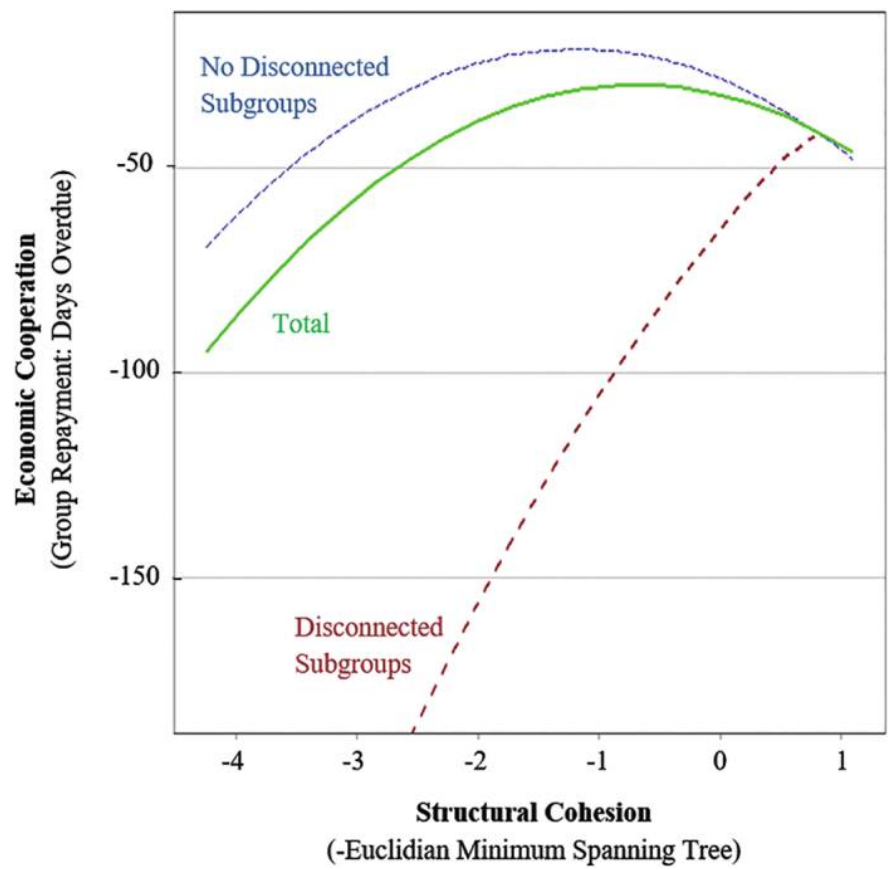

FIG. 7.-Empirical relationship of structural embeddedness and microcredit economic cooperation in Sierra Leone, 2006-11. $N=741$ loan observations nested in 406 borrowing groups (comprising 1,884 unique members). $X$-axis values denote a group's structural cohesion derived from standardized EMSTs. $Y$-axis values indicate a group's average days overdue; negative values indicate worse performance. Curves fitted with hierarchical linear regression model (see table 6 model 4). Control variables held constant at mean values.

observe that the curve fitted to groups with disconnected subgroups exhibits a significantly different shape from the curve fitted to those without. The curve for disconnected subgroups is notably steeper, indicating that a marginal increase in overall cohesion is more beneficial for groups with disconnected subgroups.

To test the robustness of the empirical findings to our model selection, we considered alternative statistical models: Tobit regression (considering early repayment and default to be censored data) and discrete-time event history models (based on risk of default). The results are substantively the same (see app. A). We also performed additional analyses to verify that the models are correctly specified. Appendix A contains further detail on log transformation of the dependent variable, variance inflation factors, and tests on the effects of loan officers.

In contrast to a social interpretation, one might question whether the effects of structural embeddedness result from financial performance covariance 
associated with spatially proximate clients. As a first step, we included control variables in the statistical analysis for business type diversity, or lack thereof, and found that business type diversity does not have a significant effect on group repayment. We tested this issue further by considering spatial autocorrelation of performance regardless of business type. For example, perhaps negative financial shocks have occurred to certain spatial areas of the city over time. Cohesive groups or disconnected subgroups that are spatially concentrated would be at greater risk of members simultaneously unable to pay. We test this possibility by analyzing the spatial autocorrelation of the performance of all 741 loans in the principal data set. We use a standard measure of spatial autocorrelation, Moran's I (Moran 1950). The statistic is applied to yearlong performance windows from 2006 to 2011. The Moran's I statistic is consistently insignificant with a mean $P$-value of 0.73 over the six years, indicating that loan performance in this city is not spatially autocorrelated. See appendix B for additional detail.

An additional potential concern is whether the results are driven by groups intending not to repay from the outset (i.e., ex ante collusion and strategic default). Recall that groups are formed through a self-selection process. It is possible that borrowers who do not intend to repay self-select each other. If strategic collusion occurs more often in certain group structures, this could confound the analysis. Poor group repayment could predominantly reflect intentional collusion rather than failure to cooperate. We are able to address this question directly with the quantitative data by further examining the monthly repayment patterns for each group. One can assume that if a group was formed with the intention of taking advantage of the microfinance institution, the group's repayment pattern should exhibit early default, that is, within the first month or at least within the first half of the loan. In appendix F, we apply a conservative filter excluding potentially collusive groups. The results indicate that ex ante collusion and strategic default is relatively rare in this data set, occurring in $1.1 \%$ or less of the disbursed loans. ${ }^{22}$ When potentially collusive groups are removed from the analysis, the substantive results remain the same.

\section{ETHNOGRAPHIC ANALYSIS}

We have shown that different measures of a microcredit group's structural embeddedness are correlated with members' economic cooperation. The statistical results supported the three hypothesized relationships: (1) Groups

\footnotetext{
22 The low rate of ex ante collusion in the data set probably derives not only from peer screening but also successful group screening by the microfinance institution. Loan offcers are trained to screen out potentially collusive groups by interviewing clients, verifying business locations and stability, checking for evidence of default at other microfinance institutions, etc.
} 
with low levels of structural cohesion, as well as those with very high levels of cohesion, perform worse than those with moderate levels. (2) The existence of disconnected subgroups is correlated with worse economic cooperation. (3) Overall group cohesion moderates the effect of disconnected subgroups on cooperation. Each of the hypothesized relationships was based on propositions developed from existing literature regarding the effect of social structure on the ability and willingness to sanction group members. The ethnographic fieldwork provides an opportunity to gauge the veracity of the underlying propositions and investigate the causal mechanisms in greater depth (King et al. 1994). ${ }^{23}$

The ethnographic analysis involves the most granular data sample of our nested design, valued for the ability to penetrate deeper into the workings of individual units and strengthen a study's internal validity (Small 2011). This methodological approach is particularly relevant for attempting to understand willingness to enforce on members of a microcredit group for two reasons. First, how one may go about socially punishing a friend or work colleague is a sensitive topic. Different data collection methods may affect the respondents' trust in the research method, for example, the likelihood of data confidentiality (Berg and Lune 2011). We invested effort in building trust with the interviewees, answering their questions, and giving them a better sense of the research motivation and use of the information. Second, the mechanisms of informal enforcement are highly context dependent, particular to the personal relationship and situation. How one may apply a motivating pressure to a friend versus a work colleague may occur in significantly different ways and could easily be lost in more coarse-grained datacollection techniques.

Our qualitative data consist of semistructured interviews with microcredit group members and microfinance institution staff in Sierra Leone. Client interviewees were drawn from the same microfinance institution as in the quantitative data sets. Groups were randomly selected from those that had been engaged in borrowing within the last six months (as of April 2011). We conducted interviews with 64 microfinance clients. Interview time totaled 42 hours. Ninety-four percent of the clients were female, reflective of the organization's focus on women (84\%). All names in the text are pseudonyms, for client confidentiality.

We also conducted nine interviews with staff of the organization, including two executive directors, two loan portfolio managers, and five loan officers. Four of the nine staff interviewees were women. Interview time of microfinance staff totaled 14 hours. This provides a critical understanding of how the organization's practices shape the observed group behavior and

\footnotetext{
${ }^{23}$ We are using the term "ethnographic" as characterized and demonstrated by Geertz
} (1973), Uzzi (1996, 1997), and Huberman and Miles (2002). 
also informs the interpretation of the recorded loan portfolio data in our statistical analyses. We conducted additional interviews with executives and loan officers at three other microfinance organizations in Sierra Leone to verify whether the organizational practices and general group behavior experienced at the principal organization were typical; the organizational practices and reported group dynamics were highly similar.

Each of the hypotheses in this study were based on two underlying propositions regarding a group's $(a)$ ability to sanction and $(b)$ willingness to sanction. We investigate these propositions by using the ethnographic data to answer the following questions. First, do the qualitative data indicate that there are relationships between a microcredit group's social structure and its ability or willingness to enforce economic cooperation? ${ }^{24}$ Second, if so, what are the specific mechanisms underlying the behavior? Third, what are the consequences of these behaviors on collective outcomes?

\section{Structural Cohesion and Enforcement Ability}

Even though all the groups were formed for the same primary purpose of joint-liability loan repayment, we found substantial variation in the groups' social structures. To better understand the relationships that are front of mind in this context, we asked clients open-ended questions regarding how they knew their other group members. As noted previously in the statistical analysis section, clients typically reported social connections based on personal relationships (e.g., long-term neighbors, friends), interaction in community organizations (e.g., mosques, churches, savings groups), and business contexts (e.g., selling side by side in the market). These connections produced groups with notably different levels of structural cohesion, as typically theorized in the literature. The concept of multiplicity of tie type was frequently expressed in terms of layers of different shared activities (Feld 1981). Here a borrower description from a highly cohesive group illustrates both high tie density among members and multiplicity of tie type: "Every day we see each other. Day and night we see. ... This one, she is my sister-in-law. This one, she is a neighbor to me. . . We used to discuss issues for our businesses, things that can make us really prosper. We have plans to put things in place that will help us in our progression.... We cook, we share food together.... We go to the same mosque. The mosque is very close to us.... We take care of each other's children. . . That's why we form a group."

${ }^{24}$ To reduce the risk of confirmation bias, the coding of enforcement behaviors was done separately from the coding of group structures. Interpretation of the data allowed for the possibility that the occurrence of enforcement behaviors would not relate to group structure as hypothesized. The most common behavioral patterns found in the ethnographic data are those presented in the text. 
In contrast, we also encountered many groups that were only weakly cohesive by comparison. Such groups were often formed through an informal referral process. A borrower describes how she was invited to join a group in which she did not previously know the other members: "I knew her because we are doing the same business, while I was doing my business in the Big Market. She met me there, and talked to me about business. And then I accept and I joined her in the group. We went together to the office [microfinance organization]. . . Then we met everyone [other group members]." In such groups, instead of a multiplicity of tie types and reinforcing connections, members may only have a single connection to the others through the marketplace. While these examples illustrate the variation between highly cohesive and weakly cohesive groups, this is not to suggest that we only found cohesion existing at these extremes. Our ethnographic research indicated that there is a range of intermediate levels as well.

How does such variation in a microcredit group's structural cohesion affect its ability to enforce economic cooperation? Our ethnographic analysis suggests that members use three main enforcement mechanisms: (1) social pressure, (2) reputation and embarrassment, and (3) ostracism.

Social pressure.-A widespread form of enforcement was colloquially referred to as "pressuring," "cajoling," or "pestering." If we apply Hechter and Opp's (2001) definition of sanctions, we should also include rewards for positive social behavior. Positive pressure was described by clients as "encouraging" or "supporting" other members. One client describes her attempt to elicit repayment using pressure: "I put pressure on her, I continue to pressure her so she would pay. It continues until when we went to her mother... We meet her in her mother's house. . . We continue to go to her father, then to her mother's house to pay.... Normally, I used to go with [another member]. At times I go there alone. . . Then apply more pressure to pay."

We found that structural cohesion increases the ability to apply social pressure to microcredit clients by increasing the frequency of interaction and the amount of sanctioning opportunities. Multiplex ties provide more opportunities between the same individuals in different contexts, and greater tie density provides more opportunities between members. The combined difference in sanctioning opportunities across groups was substantial. Here a member of a highly cohesive group estimates the frequency of their interaction: "We sit down together and talk and laugh. We eat together. . . We see each other every day. ... We see [each other] more than 10 times a day." This can be contrasted with the naturally occurring sanctioning opportunities in a weakly cohesive group. A borrower describes her typical interaction: "We see each other monthly. At times we see each other after every two weeks. When it's time for me to pay, we meet as a group. And we select someone who will go back [to the microfinance organization] and pay." 
Clients explained that social pressure is typically not a single event but more like applying regular heat to boil water. Applying pressure sporadically often resulted in unsuccessful shifts in behavior. A client who attempted to visit group members twice a month noted that the "others are always grumbling" and "giving me problems."

The interviews highlighted that successful enforcement is a function of required effort. If the effort required to pressure a member consumes more of the client's limited time and energy, it is more likely to decline over time. The increased interaction resulting from structural cohesion requires less purposeful creation of enforcement opportunities. Clients in weakly cohesive groups were more likely to mention that "I grow tired" of pressuring or "I'm constantly chasing people."

Reputation and embarrassment.-Another common form of sanctioning in microcredit groups was public embarrassment and the resulting loss in reputation. Losing face in public poses both psychological costs to the borrower, for example, "they brought shame to me," as well as financial costs in terms of reputation damage, "we know that she is not a serious person."

Borrower descriptions revealed a progression of public actions one would typically take to draw attention to a noncompliant member. Common examples with increasing severity were (1) informal discussion among community members, (2) requesting a local community elder to arbitrate the dispute, and (3) summoning the police to take a delinquent member to the local court. It is interesting that some of these methods appear to be relying on external enforcement; for example, if you sue a member in court his or her assets might be repossessed and liquidated to compensate for the overdue balance. However, in this context, the limitations of the legal infrastructure do not allow for this to be practically implemented. Rather, borrowers emphasize the role these events play in terms of public embarrassment and social stigma. Here a borrower describes her concern of being taken to court: "When we decided to take this loan, we are always afraid of embarrassment. We don't want to be embarrassed, to go with the police from one point to another [from home to court]. We are always afraid. .. . In fact, we see the embarrassment of others' groups." For microcredit clients concerned with public reputation, there are numerous reasons why these public sanctions are more salient in structurally cohesive groups: cohesion increases the flow of gossip (Merry 1984), public awareness of deviant behavior (Coleman 1988; Ostrom and Walker 2003), and the indirect value of reputation (Nowak and Sigmund 1998).

Ostracism.-Exclusion was the other common threat (and implemented sanction) in microcredit groups. The ethnographic analysis revealed that ostracism takes on three different forms in this context and does not typically involve full exclusion from the community. Rather, ostracism occurs in 
terms of (1) microcredit group membership, (2) a business community, or (3) selected social groups.

The most common form of ostracism was expulsion from the formal microcredit group. Recall that microcredit loan cycles are typically short (i.e., less than one year in this context) and progressive, substantially increasing in loan amount. An ostracized member loses access to future loan cycles with this microfinance institution. Colloquially, members use phrasing such as "we decided to kick her out of the group." More severely, a group may choose to shun a defaulting client not just from the credit group but from the market community. For example, Amina belonged to a group consisting of members who ran petty trading stalls in one of the smaller markets. When she defaulted on the group, she was no longer welcome to do business in that market. Amina left and set up her stall in a different part of the city. Even though there are numerous local markets in this relatively small city, transitioning is burdensome and costly. In the most severe cases, a member may be ostracized from a social or friendship network. Fatmata was deemed by her group as a "trouble maker." She was seen as having brought embarrassment to the group. Her default resulted in the severing of their personal friendships: "That's why we are no more friends. . . . It is because of the loan." Later that year, Fatmata decided to move to another neighborhood.

Our fieldwork indicated that there was considerable awareness of the different forms of ostracism and that they were used discriminately. Borrowers often distinguished in which context the relationship was affected. One client described, "I will not do business with her again, but it does not affect our friendship." In extreme cases, a delinquent member may be excluded from all three of these group types.

The granularity of the ethnographic data indicated how social structure shapes the effectiveness of ostracism. Cross verification of interviews indicated that there was considerable disagreement about who was at fault and who was ostracizing whom. Community consensus on expulsion was rare; more typically, a subset of borrowers chose to cut or weaken a particular type of tie. Consequently, the variation of social structure across microcredit groups determines the severity of consequences. A close-knit network is more difficult to re-create than a loosely connected group of referrals. We found that the value of the threat of ostracism depends greatly on the social structure from which one would be potentially excluded.

Structural Cohesion and Enforcement Willingness

Detailed accounts of financial hardship and group choices illustrate that one's ability to sanction does not consistently mirror one's willingness to 
sanction. Moreover, willingness to enforce tended to be weakest in highly cohesive groups. Lack of enforcement was most often expressed through empathetic accounts of another member's difficulties, for example, health problems, family trouble, or slow business sales. Here a member of a cohesive group describes another borrower's difficulty: "It was unfortunate for her that we lost her husband. ... She decided to come back from the funeral ceremony. After the funeral ceremony I met her. Then we tried to arrange the payment and give her a time. ... She did not pay the remaining balance of 20,000. But I decided to leave her alone." Other cohesive groups recounted similar experiences in which the group dynamic shifted to leniency. For example, a member of another group struggled with a sickness in which she had to visit the hospital regularly. Comembers described that enforcement was not socially appropriate. One member said, "Why so much embarrassment for such a small amount of money?"

However, these kinds of empathetic descriptions were much less common in weakly cohesive groups. It seems unlikely that lesser known community members genuinely experience less difficult life events than other members. Rather, structural cohesion increases communication and story verification, enhancing members' trust and personal regard for each other. The extent of this change in interaction was evidenced by cohesive groups' willingness to pardon delinquent behavior even when it was not a result of external misfortune, suggesting that increased cohesion can go beyond an increased ability to audit to cause a more substantial shift in the accepted norms for enforcement. For example, a borrower of a cohesive group blatantly misused the money to buy a motorbike rather than invest it in her petty trading business as per the loan terms. A member described how "she ate the money" and "we were angry with her." But they were "also sorry for her" and did not make her repay.

The ethnographic analysis revealed that highly cohesive groups are more likely to employ a social logic regarding enforcement decisions rather than an economic logic. In these groups the financial transaction is often deemed of secondary importance to the social relationships. The decisions incorporate the depth of personal history and multiplex nature of their relationships. A member of a cohesive group described why strict pressure was not appropriate: "Our members of the group undergo the same constraints. So I don't want them to strain. . . You know business is a rise and fall. At times when you bring the business, it sells very fast. But when it happens that it goes very slow and we are about to go and pay, then we assist the individual." The ethnographic data provided evidence of numerous groups engaging in trading social approval for approval, rather than approval for compliance (Flache and Macy 1996). This theoretical distinction helps clarify why cohesive microcredit groups may regularly fail to enforce repayment. 
In contrast, willingness to punish delinquent members was much more prominent in moderately or weakly cohesive groups. Members were less hesitant to risk damaging the social relationships by sanctioning. The story of Mabinty, a member of a weakly cohesive group, exemplifies this trend. Her group formed through loose business connections in the market. They came together "so we can work the money with each other." Mabinty was described by other community members as having health problems. In a more cohesive microcredit group, this might have been viewed as grounds for nonenforcement. However, her group members aggressively pressured her to repay. One member described it as follows: "Some of them, they bring their money, they pay their money completely. Why should [Mabinty] not pay? I keep on chasing [her] just to pay this money. . . . We go to [her] house and place of business in the market place... We cajole her, we keep talking to her, [but] she refuse."

The members further escalated the issue to a local community elder. Feeling the immensity of the social pressure, Mabinty decided to flee the community without telling the other group members. However, they heard of this through other social contacts: "Actually, she did not tell us anything. All of a sudden she decided to run away. She was preparing to go and we got the information. We are able to catch her at the [road] intersection." They found her there with packed bags. She swore that she would get the money now, but the other members did not want the pressure to lighten: "She told us that she wants to go and collect the money. And we said, this is not our agreement. This is the day." They would not allow her to physically leave their sight. Eventually, "She called someone [family member] to come and sign for her, so that she can pay the money." Having finally been pressured into finding a way to repay her portion, she was removed from the group: "After we finished paying, we kicked her out."

The experience of Mabinty illustrates a common finding in the data: groups consisting of loose, simplex connections are more likely to view the relationships as serving a functional purpose. Desmond (2012) theorizes the concept of "disposable ties," typically occurring between new acquaintances with an accelerated intimacy. In contrast to a predominantly economic transaction, resource exchange is interwoven with the social relationship, but ties usually have a short life span. Once strained, the ties are typically burned and discarded. We saw ample evidence of this in the microcredit groups. Coborrowers without multiplex or reinforcing relationships were more likely to aggressively pressure each other, squeeze payment, and then sever the connection. One borrower described how she made no attempt to maintain a relationship after pressuring the member to pay: "We used to see her in the market, but now she is not in the market anymore. It's been so many days without seeing her since she was embarrassed for this money. Just after when she completed paying, then she disappeared." 
In contrast, members of highly cohesive groups often maintained strong personal relationships after the loan, even if it ended because of a member defecting. Such clients often said that they would not do business with the defecting member again but that it did not disrupt the other personal ties between them. A member describes it as follows: "Even though she was late to pay ... we never asked her to leave the group. We only tried to cajole her so that she would pay this money. . . It does not change our friendship, but it did disturb us in the office [of the microfinance organization]." Consequently, the same structural group features that often enhance the ability to effectively sanction (i.e., tie multiplicity, density, closure) consistently reduce members' willingness to use them.

\section{Compliance Enforcement with Disconnected Subgroups}

The fieldwork provided evidence that another structural feature heightens the tension between ability and willingness to enforce: the disconnected subgroup. It was common to find microcredit groups with nonhomogeneous cohesion such that subgroups were connected more strongly internally than to the other subgroup. We found these structures arising from neighborhood cliques, friendships spanning multiple social groups, and business connections between multiple markets.

We found that microcredit clients were more willing to sanction members of the out-subgroup. They would often try to use the same enforcement mechanisms as discussed previously: social pressure, reputation and embarrassment, and ostracism. For example, one group included a disconnected subgroup of two women living near each other on the same street. They had not paid on time, complaining of "slow business sales." The other members of the group typically referred to them collectively as "stubborn old women" and went to their homes as a group to "threaten them." To avoid the embarrassment of being escorted by the police to court, they complied and paid their shares. Numerous cases in the ethnographic data supported the theory that relatively minor differences may result in the development of an outgroup bias and increase the willingness to punish (Brewer 1979; Frank and Yasumoto 1998).

However, it was more common for attempts at sanctioning another subgroup to fail. The lack of social connectivity across subgroups posed several enforcement limitations. First, the reduced interaction and communication across subgroups made it more difficult to track and sanction minor deviations from compliance. Issues that could be resolved by consistent social pressure in other groups were more likely to grow into substantial repayment problems. For example, one borrower described how the limited information flow from the other subgroup made it easier for them to be deceived. Ultimately the group fractured, and one subgroup fully defected. A member of the 
remaining subgroup described what transpired: "That was the same plan they took. They used the same plan to make an excuse. They said they were going out to buy business [items out of town]. We said, 'No problem, you can go out.' But then . . . after a while, we do not see them back. . . . After three months, they dissolved. You can't see any of them."

Second, disconnected subgroups limit the effectiveness of embarrassment and public shaming as a punishment mechanism. The structural gap between subgroups makes the transmission of reputation effects less likely, and the interviews indicated that clients weight the rebuke of out-group members more lightly. One borrower, Ibrahim, described how he had attempted to pressure members of a different community in the same way he had done with his neighboring members: "I tried to influence. . . . I tried to cajole. . . But no way." The pressure persisted for months and was often purposely administered in public. Ultimately Ibrahim was unable to convince them to cooperate.

Third, the threat of social ostracism is less powerful to members of an outsubgroup. While it is true that members of an out-subgroup can still be threatened with ostracism from the formal microcredit group (and frequently were), social exclusion from a distant group or the severing of weak market relationships was less concerning. The result is that groups with disconnected subgroups lack some of the enforcement tools. Memuna described how her loan involved a disconnected subgroup. She did not know their names, but could recognize them if she saw them in the market. When the subgroup members were unwilling to pay, she "kicked them out" of the group and stopped visiting them. Memuna wanted to "show grievance towards the group" but believes that "they don't feel bad about it. . . . They deliberately did not want to pay." This example illustrates a trend in the data that, although often eager to do so, members of one subgroup are not able to effectively sanction those of another subgroup.

In sum, the ethnographic analysis provided confirmatory evidence that the tension between ability and willingness to punish is influenced by features of a group's social structure. The personal descriptions brought to life the underlying sanctioning mechanisms. Although ability and willingness are often in conflict, the nature of the underlying social mechanisms suggests that there are systematic tendencies. The consistency with which a group member grants an "enforcement exception," or lack thereof, allows one to form more accurate expectations for aggregate cooperative outcomes.

\section{DISCUSSION}

The importance of cooperation in human societies has motivated substantial research, and we are now equipped with an extensive and illuminating set of factors known to affect collective behavior (Dawes 1980; Kollock 1998; 
Ostrom 2000; Pletzer et al. 2018). The insights are relevant to cooperative dilemmas occurring in a wide range of contexts: organizational behavior (e.g., corporate teams in which the economic return is shared but effort is an individual choice), political and social movements (e.g., citizens considering free riding on the political action of others), and community programs (e.g., the extent to which a parent will personally contribute to a local school program). However, researchers have noted that in order to advance this broad area of research, we need to address our limited ability to integrate potentially conflicting factors in order to predict which mechanisms are most likely to dominate the collective outcome (Fehr and Gintis 2007; Hedström and Bearman 2009; Baldassarri 2015).

Essential to our understanding of these group dynamics is the role of informal enforcement. How often will the corporate team member bother a coworker for not putting in enough effort? To what extent will a fellow citizen be stigmatized for not casting a vote? Will parents stop socializing with neighbors who are not fully engaging in the school program? In all these cases, actors must decide to what extent they will play the role of enforcer.

This study has argued that a group's social structure often produces conflicting enforcement behaviors, but when accounted for, the collective outcome exhibits systematic trends. A known dilemma in cooperative research is that ultimately actors must contribute on at least two levels for sustained collective benefit: the first level, contribution to the original good, and the second level, contribution to enforcement (Heckathorn 1993). A challenge that arises when attempting to map social structure to cooperative outcomes is that changes in social structure tend to have inverse effects on these two levels. A key source of this conflict is that the same social mechanisms that naturally increase the ability to sanction (e.g., increased social interaction and multiplex relationships) simultaneously decrease the willingness to sanction the defector. In this closing section, we will discuss how a greater understanding of these relationships (1) expands our existing knowledge on group processes and collective outcomes, (2) offers practical implications for cooperative dilemmas, and (3) raises new questions for future research.

First, this study confirms substantial prior research suggesting that social connectedness enhances the ability to sanction through an increase in opportunities and effectiveness (Homans 1950; Hechter 1988; Coleman 1990). However, effective opportunities in themselves are functionally different from credible threats or implemented actions. This distinction between ability and willingness has been noted in the cooperative literature, suggesting, either explicitly or implicitly, that both are necessary components of effective enforcement (e.g., Fehr and Gächter 2000; Ostrom 2000; Reuben and Riedl 2013). Specifically, we have advanced the idea that social structure is a key determinant of these two tendencies, and a change in one is likely to accompany a change in the other. Accounting for this interdependence substantially 
shifts our expectations for collective outcomes. The ability-willingness tension induces cooperative trends that are nonmonotonic and highly sensitive to interaction effects. We expect that this theoretical distinction may reconcile numerous empirical studies on cooperation that appear to produce conflicting results (e.g., Wydick 1999; Paxton et al. 2000; Hermes, Lensink, and Mehrteab 2005; Al-Azzam et al. 2012).

To make use of this theoretical distinction, another important question is raised. When a group structure exhibits ability and willingness tendencies that are not reinforcing, what logic should we follow to form specific expectations for the collective outcome? In this study, we found it beneficial to start by explicitly considering how a feature of a group's structure separately affects ability and willingness to sanction. However, when combining the two, we note that they should not be viewed as additive factors in relation to the cooperative outcome. Rather, as they are both necessary, the lesser of the two limits the extent to which social sanctioning can enhance cooperation in a group. This approach allows one to derive testable hypotheses that better reflect our understanding of the interdependence of ability and willingness to enforce cooperation. We suggest that this method may be fruitfully applied to other features of a group's social structure.

In this study, we took steps toward exploring this possibility by deriving expectations based on a group's structural cohesion, the existence of disconnected subgroups, and the interaction of these two features. In the context of group lending in Sierra Leone, these features both exhibited a tension between ability and willingness to enforce. Moreover, the variety of collective outcomes confirmed the importance of not assuming additive linear relationships. The group lending data showed that optimal group structure in terms of repayment consists of moderately cohesive groups without disconnected subgroups. Notably, we did not find peak performance correlated with highly cohesive groups, suggesting that moderate cohesion provides beneficial levels of both ability and willingness to sanction. However, if a group can be characterized as consisting of disconnected subgroups, the baseline ability to sanction is so much lower that an incremental increase in overall group cohesion offers a more strongly positive effect. As a result, the worst group structure on average can be characterized as having disconnected subgroups and low overall structural cohesion.

To what extent do we expect that these relationships are generalizable beyond their observed context? For example, will a corporate team exhibit the same enforcement trade-offs? Will a political group struggle with social enforcement across factions? The theoretical foundation suggests that the tension between ability and willingness to enforce naturally arises from underlying social mechanisms and that variation in social structure predictably shifts the balance. However, whether and at what point the tipping point is reached is highly context driven and dependent on the group setting, 
the nature of the good itself, the relative trade-offs between the future relationship and cooperative benefit, and so on. It would be inappropriate to expect that a model of such a complex phenomenon as collective action can be stripped of its basic contextual assumptions and still provide insight (Oliver 1980). Rather, the tension to enforce cooperation should be interpreted in relation to these contextual factors. Imagine a cooperative setting in which the baseline level of structural cohesion is comparatively low and does not frequently reach levels at which the value of the relationships outweigh the good. This could be found in work teams consisting of new employees in an organization, for example. In this case, one might expect a linearly increasing relationship between structural cohesion and economic cooperation. A study by Karlan (2007) provides a good example of this in the microcredit context. Members are quasi-randomly assigned to joint-liability groups rather than self-selected, resulting in less extreme values of social cohesion and overall increasing returns to spatial propinquity.

In regard to practical implications, the results indicate that if social collateral is intended to dissuade loan default, it does offer value up to a point, but once a threshold of cohesion has been surpassed, its effectiveness reverses and declines. In addition, the value of social collateral is substantially weaker if groups have a social disconnect. Therefore, one might look at the observed trends and be left with the idea that moderation should be the goal because moderately cohesive groups without a structural cleavage performed best. While this point is observed in the data, attempting to manipulate group structure to reach that point may not be a trivial task in practice. For example, microfinance institutions often equip loan officers with simple heuristics, such as "the better group members know each other, the better the group." We see that such a heuristic immediately places the organization in a safe space; that is, high structural cohesion narrows down the average propensities to moderate performance. This occurs because the risks associated with overembeddedness and underembeddedness are not symmetrical relative to the peak. The downside of low-cohesion groups poses significantly greater economic risk. Certainly, it is a much more difficult search task for loan officers to identify moderately cohesive groups without disconnected subgroups than to simply identify highly cohesive groups. In this case, microfinance institutions may be setting appropriate practices given their limited resources. Further fine-tuning of their group lending practices would depend on the availability of additional resources. In like manner, other organizations and social groups may find value in developing heuristics that appropriately balance the trade-offs associated with enforcement ability and willingness in their specific context.

The observed cooperative behaviors in this study also offer insight to group formation and member preferences for enforcement. Substantial research has suggested that selective interaction is one of the key mechanisms 
supporting the evolution of cooperation (Nowak 2006; Santos, Pacheco, and Lenaerts 2006). In the microfinance context, group members often have substantial flexibility in whom they choose as group members. In this study we see a tendency for groups to be overembedded, that is, exhibit levels of structural cohesion above the threshold that improves economic performance. This may partially derive from the microfinance institution's heuristics as noted above, but it may also stem from the preferences for whom members wish to partner with. Do members prefer to join a group in which there is some expectation for soft enforcement? One may be aware that group norms for rigid enforcement are equally likely to be applied to themselves. Is the inferred ability to back out of a group agreement a preferred feature, even though it may reduce the likelihood of maximizing the economic outcome? Member selection in relation to compliance enforcement is an open question deserving further research. Bryan, Karlan, and Zinman (2015) have expanded a group selection model to include preferences for partners' malleability type (i.e., their susceptibility to social pressure). Understanding the selection criteria in relation to compliance enforcement offers wide application to alternative collective-action settings such as selfselection into school systems, neighborhoods, and working groups.

This study's external validity has benefited from the focus on field data but has also posed some limitations deserving further research. First, we note that the causal linkage between structure and the ability-willingness tension should be further examined. Although this study examined longitudinal data, we were limited in treating variation in group structure as across groups rather than variation within groups over time. Alternative methods could probe the effect of shifts in group structure among the same members through evolving panel data or experimentally manipulated groups. Second, we have empirically focused on collective behavior in small groups. Group size is a key contextual variable in cooperative research (Dawes 1980). Large groups may exhibit different relationships between social structure and enforcement behavior. For example, although we found that disconnected subgroups produce a consistently negative effect on the collective outcome, other research has suggested that social fragmentation may offer benefits for norm enforcement, dependent on the interaction of network structure and group size (Macy 1991; Kim and Bearman 1997; Hanaki et al. 2007).

In closing, this study encourages a fertile area of research in which exceptions in compliance enforcement are being better understood as systematic behaviors. Consider the behavior variation in highly cohesive groups (Flache and Macy 1996; Horne 2007), the substantial role of "conditional cooperators" (Fehr and Gintis 2007; Fehr and Schurtenberger 2018), or member selection based on their susceptibility to social pressure (Bryan et al. 2015). In this vein, researchers are uncovering the causal basis for what 
initially appears to be noise in cooperative behavior. In the case of group lending, leniency in not punishing a member struggling to contribute financially may seem like an outlier. However, we suggest that there are consistent structural conditions that promote a logic of aggressive enforcement ("I keep on chasing [her] just to pay this money") over one of prosocial leniency ("but I decided to leave her alone"). Research that delves deeper into the structured component of social preferences and enforcement variability offers continued advancement in our understanding of collective behavior.

\section{APPENDIX A}

\section{Robustness of Model Selection}

Distribution of the dependent variable.-We performed additional statistical analyses to test whether the results are sensitive to alternative treatments of the dependent variable. In the principal analysis, we used maximum days overdue for each group loan as the dependent variable (see model A1 for a summary). In model A1, all values are as recorded by the microfinance institution (lateness coded negative). The distribution has a negative skew with a higher frequency of groups paying on time (see fig. A1). We took several steps to verify that the skewness of the distribution was not adversely affecting the model results. We calculated Cook's distance and reran the analysis without the observations with potential high influence; the results were not significantly changed. We performed a logarithmic transformation on days overdue, to reduce the skewness of the distribution. See model A2 for regression results using a logarithmic transformation of days overdue. The results are substantively the same.

Alternative statistical models.-In the principal analysis, we treated the dependent variable as a continuous measure. One could question whether early payment and default should be treated differently from "ordinary" days overdue. It is possible that variation in values associated with early payment or default do not contain relevant information. To account for this we modeled days overdue as censored data, right censored at 0 (early) and left censored at -180 (default). Model A3 presents the results of the Tobit model for censored data. The results are substantively the same as the core model. Furthermore, we ran additional models indicating that the results are not sensitive to the cutoff points. For example, the results are substantively the same if the data are left censored at -90 days.

Alternatively, one could disregard days overdue and focus on the risk of default as the key indicator of economic performance. In this sense, economic cooperation would be viewed as continued repayment across loan cycles without default. We modeled this alternative with the Cox proportional 


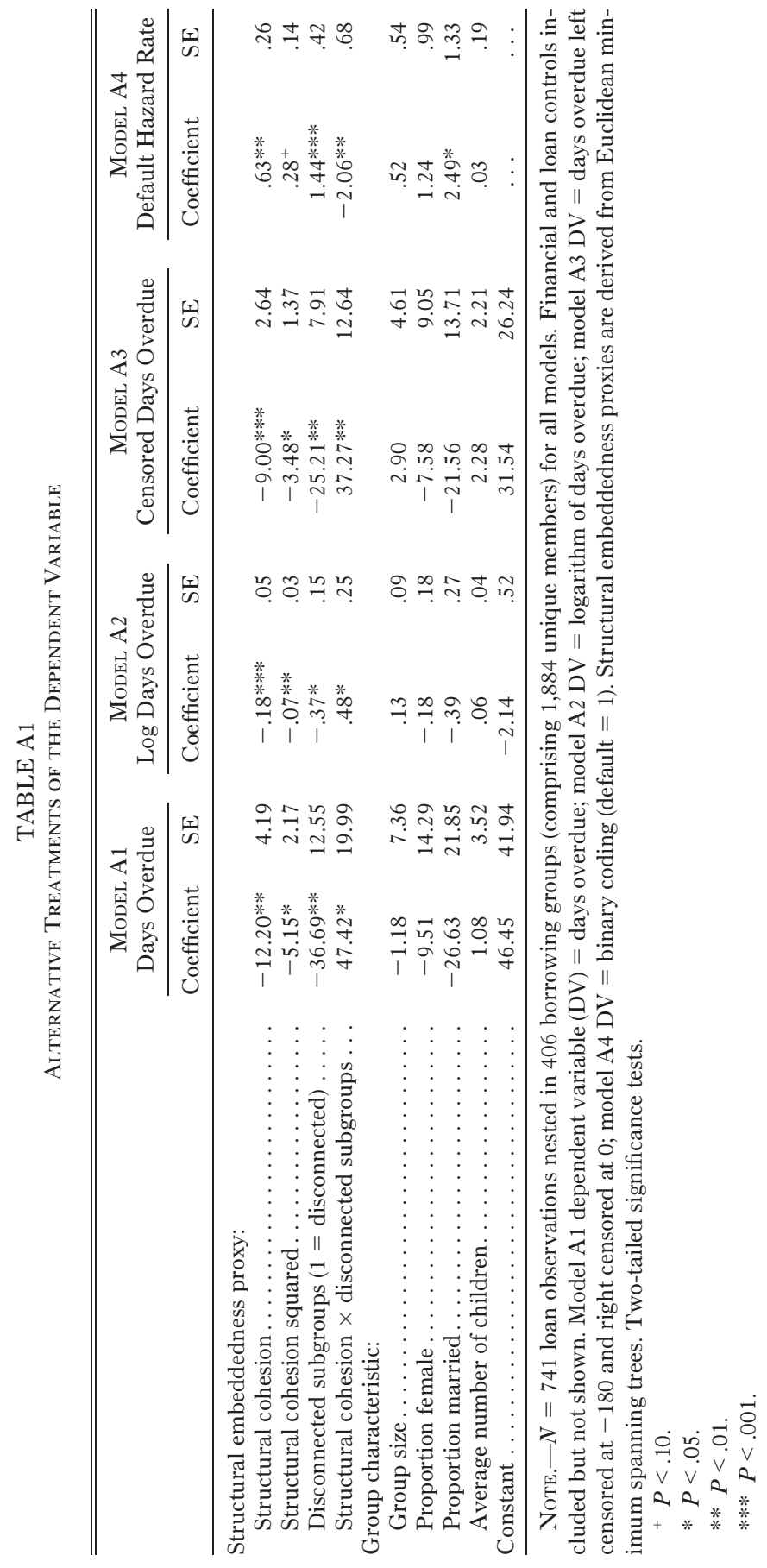


American Journal of Sociology

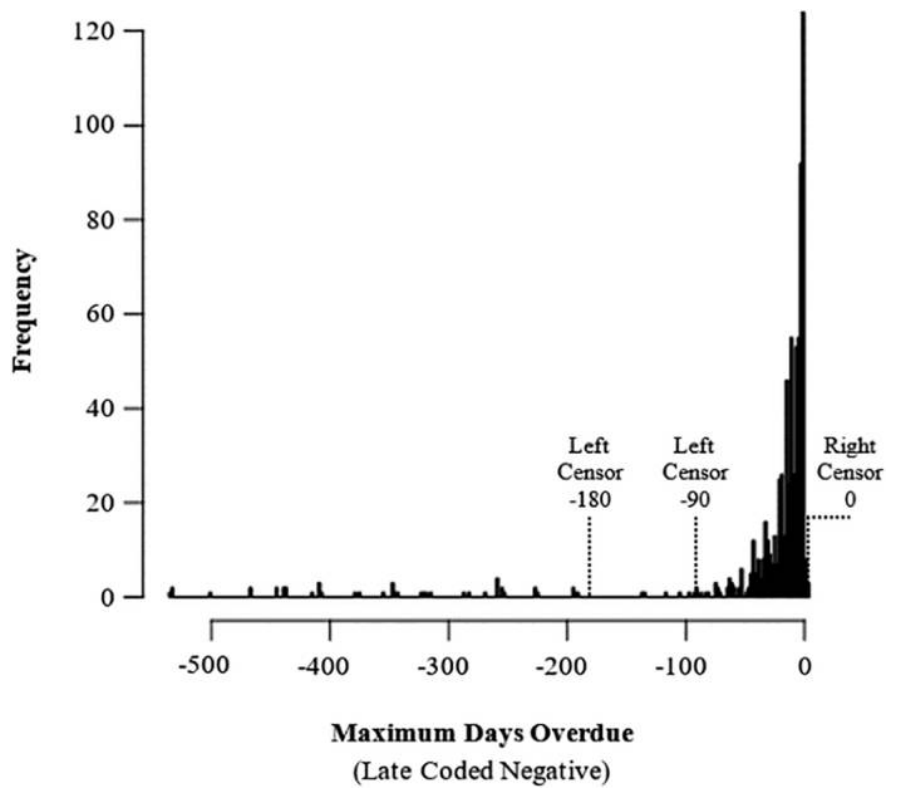

FIG. A1.-Days overdue: raw data. $N=741$ loan observations nested in 406 borrowing groups (comprising 1,884 unique members). Principal model uses maximum days overdue (raw data). In additional models (see table A1), days overdue are treated as censored data. Substantive results are the same.

model for discrete-time survival (see Allison 2014). The hazard rate is the risk of default over each loan cycle (binary coding; default $=1$ ). The Cox proportional model is well suited to this context because it addresses two censoring issues that occur in the longitudinal data: (1) a microcredit group may have not yet experienced the event (default) within the study period but could do so in the future, and (2) groups may "drop out" of the study for reasons other than default, for example, a group may not want to take a subsequent loan cycle because members' financial circumstances have changed. Accounting for these issues, the results of the Cox proportional model are presented in model A4. Note that in this treatment of the dependent variable higher values indicate worse performance. The results indicate that the effects of the explanatory variables are not substantively different from the alternative models. We prefer model A1 for its direct fit with the theoretical concepts and ease of interpretation.

Core model specification.- -We note additional tests to verify that model A1 is appropriately specified. Calculation of generalized variance inflation factors (maximum value 5.63) for the principal model indicates that multicollinearity is not a significant concern. However, we do see from the empirical results (table 6) that the controls for some loan officers are highly significant; 
notably, loan officers 2 and 4 are associated with worse performing groups. To test whether loan officers were influencing our results, we divided the data set into two subsets (one with loan officers 2 and 4, and one with the others). Rerunning the principal model on the subsets did not significantly affect the results.

\section{APPENDIX B}

\section{Spatial Autocorrelation of Economic Performance}

In the text of the article we applied the Moran's I statistic for spatial autocorrelation. We found that loan performance in our data set was not spatially autocorrelated. Figure B1 presents the results graphically, each point representing the repayment performance of a group loan. For visual purposes, we

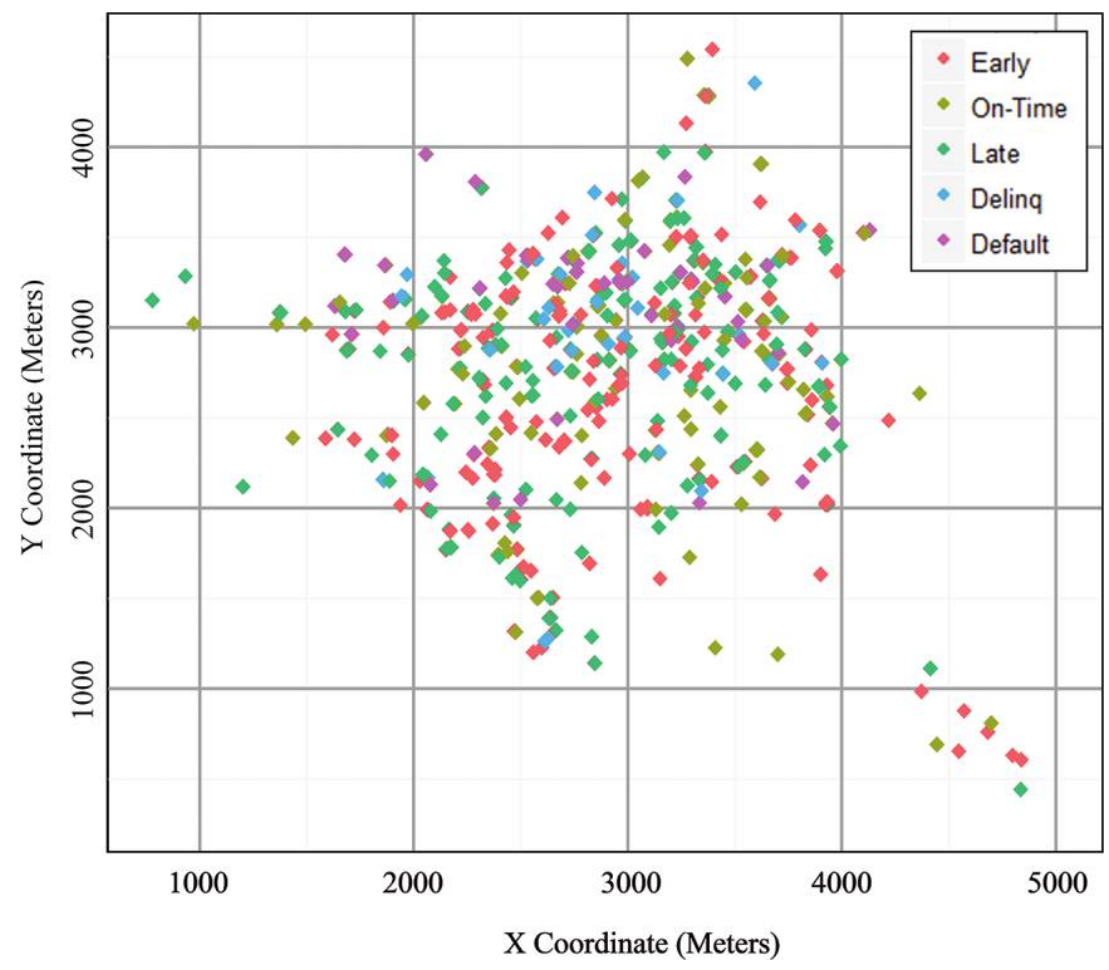

FIG. B1.-Spatial autocorrelation of microcredit economic performance in Sierra Leone, 2006-11. $N=741$ loan observations nested in 406 borrowing groups (comprising 1,884 unique members). Colors designate group loan repayment performance. Statistical analysis confirms lack of spatial autocorrelation. 
American Journal of Sociology

apply five repayment categories: early, on time, late, delinquent $(30+$ days overdue), and default (180+ days overdue). In this figure, $X$ and $Y$ coordinates are recentered to maintain client anonymity.

\section{APPENDIX C}

Partial Payment Analysis

A concern of the core quantitative analysis is that the observed relationships between group structure and economic cooperation (operationalized as the maximum days overdue before payments made in full) could potentially be driven by a systematic relationship between group structure and financial ability, rather than the hypothesized social mechanisms. In this appendix, we construct an alternative measure of a microcredit group's economic cooperation that minimizes the role of a group's financial ability to repay. We rerun the core analyses and present the results.

All loans in this study are scheduled for monthly repayments, lasting between 6 and 12 months. If a group does not have the full amount by the scheduled monthly due date, the group may make a partial payment to the microfinance institution. There are no organizational requirements for a minimum amount, and groups may make multiple partial payments if necessary. Partial payments as low as $5 \%$ of the scheduled monthly amount are observed in this data set. Overall, $72.66 \%$ of groups are recorded as making at least one partial payment, indicating that it is not uncommon for groups to have difficulty making the full monthly payment.

The alternative measure of economic cooperation in this appendix leverages the possibility that if a group is cooperating but experiencing a financial difficulty, it may make a smaller partial payment. The measure is constructed for each scheduled monthly payment by using the minimum days overdue before some amount of group payment is made, partial or full. Days overdue are coded negative to reflect worse group performance.

The statistical model is similar to the hierarchical linear regression used in the core analysis; however, data are now structured at three levels. Monthly payments $(N=5,487)$ are nested within loans $(N=741)$, which are nested in groups $(N=406)$. Random intercepts are included for loans and groups. A variable to account for the number of each scheduled payment is included. The results are presented in table $\mathrm{C} 1$. We also verified that the modeling approach is not sensitive to the treatment of defaults. Monthly payments without any partial payment (i.e., full payment write-off) is relatively rare, occurring in less than $1 \%$ of total scheduled payments (22 out of 5,487 ). In model $\mathrm{C} 1$, if no partial (or full) payment was received, the payment is coded at the minimum value ( -180 days). In model $\mathrm{C} 2$, the observations are omitted if no partial (or full) payment was received. The 
TABLE C1

Hierarchical Linear Regression Predicting the Effect of Structural Embeddedness on Economic CoOperation in Microcredit Groups, Sierra Leone 2006-11 (Including Partial Payments)

\begin{tabular}{|c|c|c|c|c|}
\hline & \multicolumn{2}{|c|}{ Model C1 } & \multicolumn{2}{|c|}{ Model C2 } \\
\hline & Coefficient & $\mathrm{SE}$ & Coefficient & $\mathrm{SE}$ \\
\hline \multicolumn{5}{|l|}{ Structural embeddedness proxy: } \\
\hline Structural cohesion $\ldots \ldots \ldots \ldots \ldots \ldots$ & $-1.31 * *$ & .46 & $-.98 * *$ & .33 \\
\hline Structural cohesion squared . . . . . . . . . . & $-.61 * *$ & .24 & $-.48 * *$ & .17 \\
\hline Disconnected subgroups $(1=$ disconnected $) \ldots$ & $-3.75 * *$ & 1.39 & $-3.20 * *$ & 1.00 \\
\hline Structural cohesion $\times$ disconnected subgroups $\ldots$ & $4.39 *$ & 2.21 & $4.97 * *$ & 1.60 \\
\hline \multicolumn{5}{|l|}{ Group characteristic: } \\
\hline 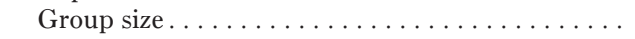 & .21 & .79 & .41 & .57 \\
\hline Proportion female . . . . . . . . . . . . . & .06 & 1.56 & -.46 & 1.14 \\
\hline Proportion married $\ldots \ldots \ldots \ldots \ldots \ldots$ & -.08 & 2.39 & .79 & 1.75 \\
\hline Average number of children. . . . . . . . . . . . & .40 & .39 & $.69 *$ & .28 \\
\hline \multicolumn{5}{|l|}{ Financial characteristic: } \\
\hline Average monthly sales . . . . . . . . . . . . . & -2.79 & 1.95 & $-3.32 *$ & 1.33 \\
\hline SD monthly sales $\ldots \ldots \ldots \ldots \ldots \ldots \ldots$ & .57 & 1.22 & $1.57^{+}$ & .83 \\
\hline Average business equity $\ldots \ldots \ldots \ldots \ldots \ldots$ & $2.54^{+}$ & 1.37 & $2.02 *$ & .93 \\
\hline Proportion petty traders $\ldots \ldots \ldots \ldots \ldots \ldots$ & 1.71 & 1.51 & .45 & 1.05 \\
\hline Business type diversity $\ldots \ldots \ldots \ldots \ldots \ldots$ & .13 & .66 & .22 & .46 \\
\hline \multicolumn{5}{|l|}{ Loan characteristic: } \\
\hline 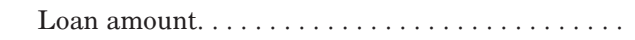 & -1.01 & .62 & -.70 & .43 \\
\hline 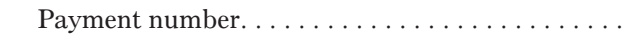 & $-.98 * * *$ & .07 & $-.74 * * *$ & .04 \\
\hline Loan cycle . . . . . . . . . . . . . . & -.55 & .47 & -.42 & .33 \\
\hline Loan officer $1 \ldots \ldots \ldots \ldots \ldots \ldots \ldots$ & -.51 & 1.76 & .45 & 1.21 \\
\hline Loan officer $2 \ldots \ldots \ldots \ldots \ldots \ldots \ldots$ & -4.29 & 2.75 & $-3.68 *$ & 1.88 \\
\hline Loan officer $3 \ldots \ldots \ldots \ldots \ldots \ldots \ldots$ & -.85 & 1.20 & -.13 & .84 \\
\hline Loan officer $4 \ldots \ldots \ldots \ldots \ldots \ldots \ldots \ldots$ & $-9.43 * * *$ & 1.11 & $-4.87 * * *$ & .77 \\
\hline Loan officer $5 \ldots \ldots \ldots \ldots \ldots \ldots \ldots$ & .51 & 1.03 & .64 & .74 \\
\hline Loan officer $6 \ldots \ldots \ldots$ & .88 & 1.45 & 1.20 & 1.00 \\
\hline Loan officer $7 \ldots \ldots \ldots \ldots \ldots \ldots$ & 1.01 & 1.53 & 1.39 & 1.04 \\
\hline Loan officer $8 \ldots \ldots$ & .75 & 3.53 & 1.37 & 2.42 \\
\hline Constant $\ldots \ldots \ldots \ldots \ldots \ldots \ldots \ldots$ & 2.46 & 4.56 & -.87 & 3.30 \\
\hline Deviance......................... & 43,902 & & 37,959 & \\
\hline
\end{tabular}

Note.-Dependent variable is days overdue before a group's partial (or full) monthly repayment. Full payment write-offs coded -180 in model C1, excluded in model C2. Model C1 (C2): $N=5,487(5,465)$ monthly group payments nested in $741(741)$ group loans nested in $406(406)$ borrowing groups, comprising $1,884(1,884)$ unique members. Structural embeddedness proxies are derived from Euclidean minimum spanning trees. Two-tailed significance tests.

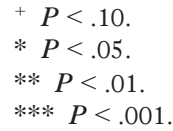

treatment of these observations does not substantively change the model results.

With the requirement for full repayment removed, the results in table $\mathrm{C} 1$ exhibit the same key relationships between group structure and economic cooperation as those presented in the body of the article. The partial 
American Journal of Sociology

payment analysis indicates that the systematic relationships are not principally driven by variation in groups' financial ability to pay.

\section{APPENDIX D}

Effects of Technology on Spatial and Social Proximity

This appendix addresses potential limitations of using spatial proxies for structural embeddedness; in particular, the effects of communication and transport technology are discussed. The most significant concern relates to the softening of the relationship between social and spatial proximity as a result of changes in communication technology. Technological advances such as the mobile phone, e-mail, and social media have made it easier to form and maintain social relationships at greater physical distances (Hampton and Wellman 2001; Lin and Atkin 2007). Although this trend in technology is undoubtable, research has found that spatial proximity still plays a fundamental role in shaping social networks. It appears that enhanced communication is most commonly directed toward maintaining local social ties (Levy and Goldenberg 2014) and tends to reinforce existing sociospatial patterns, rather than inventing completely new ones (Stephens and Poorthuis 2015). For example, college students are more likely to e-mail their peers living in the same dormitory hall (Marmaros and Sacerdote 2006), employees at Google are more likely to communicate with and influence their physically proximate coworkers (Cowgill, Wolfers, and Zitzewitz 2009), and Twitter users are more likely to follow their neighbors (Stephens and Poorthuis 2015). These examples focus on contexts in which individuals are using the latest communication technology. Most microfinance clients in Sierra Leone will not use such technology to the same extent. However, the implication is that if spatial proximity is still a basic determinant of social networks in more extreme cases of technology use, one can be more confident using a spatial proxy in the Sierra Leone context.

A second concern is the trend in increased spatial mobility (Kellerman 2012; Wegener 2013), for example, greater likelihood of long work commutes or moving residential addresses. Sampson (1988) notes that there is significant variation in spatial mobility across cultural contexts, and the role of spatial proximity in social behavior is more potent in contexts with lower mobility. Microfinance institutions, particularly group lending programs, are typically based in developing countries with lower spatial mobility of its clients (Wenner 1995; Cassar and Wydick 2010). In this study, the concern of spatial mobility is mitigated by the geographical context of Sierra Leone, providing a stronger relationship between physical space and structural embeddedness. 
APPENDIX E

Robustness of Disconnected Subgroup Threshold

Figure E1 displays the relationship between economic cooperation and the existence of disconnected subgroups. By varying the distance threshold used to define a disconnected subgroup, we can examine the robustness of the results. Across different thresholds, groups with disconnected subgroups perform consistently worse than those without disconnected subgroups.

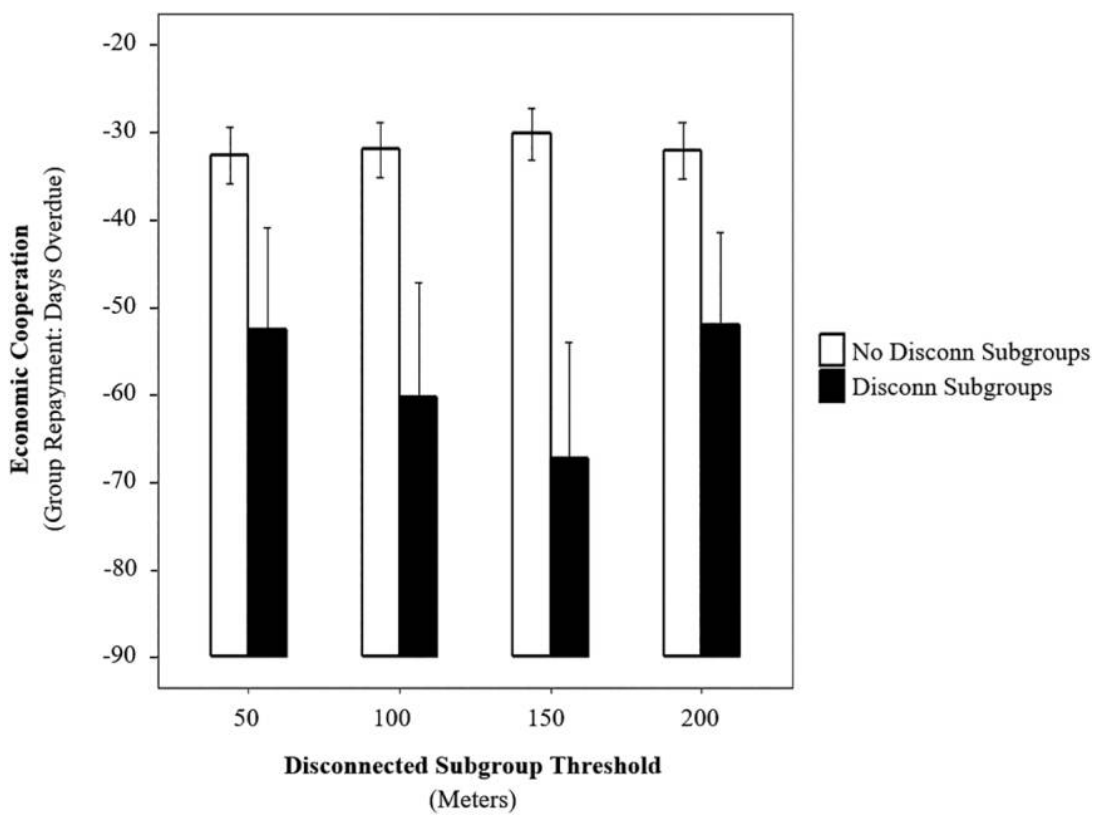

Fig. E1.-Robustness of disconnected subgroup threshold. $N=741$ loan observations nested in 406 borrowing groups (comprising 1,884 unique members). Threshold distance for defining disconnected subgroups is varied on the $X$-axis. $Y$-axis values indicate a group's average days overdue; negative values indicate worse performance. Error bars reflect \pm SEM (standard error at the mean).

\section{APPENDIX F}

Potential Collusion and Strategic Default

In this appendix we summarize additional analyses verifying that the observed results in the core model are not driven by ex ante collusion and strategic default. We assume that if a group was formed with the primary intention of receiving the loan disbursement and not repaying the microfinance 


\section{American Journal of Sociology}

TABLE F1

Hierarchical Linear Regression Predicting the Effect of Structural Embeddedness on Economic Cooperation in Microcredit Groups, Sierra Leone 2006-11 (Excluding Potentially Collusive Groups)

\begin{tabular}{|c|c|c|c|c|}
\hline & \multicolumn{2}{|c|}{ Model F1 } & \multicolumn{2}{|c|}{ Model F2 } \\
\hline & Coefficient & SE & Coefficient & SE \\
\hline \multicolumn{5}{|l|}{ Structural embeddedness proxy: } \\
\hline Structural cohesion $\ldots \ldots \ldots \ldots \ldots \ldots$ & $-12.39 * *$ & 4.10 & $-9.56 * *$ & 3.71 \\
\hline Structural cohesion squared . . . . . . . . . & $-5.41 *$ & 2.12 & $-4.55 *$ & 1.91 \\
\hline Disconnected subgroups $(1=$ disconnected $) \ldots$ & $-37.88 * *$ & 12.27 & $-43.80 * * *$ & 11.02 \\
\hline Structural cohesion $\times$ disconnected subgroups $\ldots$ & $47.53 *$ & 19.55 & $46.62 * *$ & 17.55 \\
\hline \multicolumn{5}{|l|}{ Group characteristic: } \\
\hline Group size . . . . . & .12 & 7.20 & 1.44 & 6.47 \\
\hline Proportion female $\ldots \ldots \ldots \ldots \ldots \ldots \ldots$ & -12.22 & 13.98 & -11.45 & 12.57 \\
\hline Proportion married . . . . . . . . . . . . & -25.59 & 21.37 & -14.34 & 19.19 \\
\hline Average number of children. . . . . . . . . . . & 2.58 & 3.45 & 2.36 & 3.11 \\
\hline \multicolumn{5}{|l|}{ Financial characteristic: } \\
\hline Average monthly sales $\ldots \ldots \ldots \ldots \ldots \ldots \ldots$ & -8.77 & 18.35 & -16.41 & 16.54 \\
\hline SD monthly sales $\ldots \ldots \ldots \ldots \ldots \ldots \ldots$ & -6.22 & 11.42 & -.30 & 10.34 \\
\hline Average business equity $\ldots \ldots \ldots \ldots \ldots$ & 14.26 & 12.90 & 17.52 & 11.65 \\
\hline Proportion petty traders . . . . . . . . . . . & 18.52 & 13.80 & 2.73 & 12.48 \\
\hline Business type diversity . . . . . . . . . . . $\ldots$ & -2.16 & 6.05 & -3.69 & 5.45 \\
\hline \multicolumn{5}{|l|}{ Loan characteristic: } \\
\hline Loan amount. . . . . . . . . . . . . . . . . & $-11.86^{*}$ & 5.74 & $-8.94^{+}$ & 5.16 \\
\hline Loan cycle . . . . . . . . . . . . . . . . & -3.48 & 4.42 & -4.11 & 3.97 \\
\hline Loan officer $1 \ldots \ldots \ldots \ldots \ldots \ldots \ldots$ & -7.74 & 16.41 & -4.69 & 14.74 \\
\hline Loan officer $2 \ldots \ldots \ldots \ldots \ldots \ldots \ldots$ & $-85.23 * * *$ & 24.41 & $-79.19 * * *$ & 21.91 \\
\hline Loan officer $3 \ldots \ldots \ldots \ldots \ldots \ldots$ & -12.22 & 10.82 & -6.86 & 9.72 \\
\hline Loan officer $4 \ldots \ldots \ldots \ldots \ldots \ldots \ldots$ & $-82.10 * * *$ & 10.00 & $-64.83 * * *$ & 9.06 \\
\hline Loan officer $5 \ldots \ldots \ldots \ldots \ldots \ldots$ & 7.05 & 9.45 & 7.40 & 8.48 \\
\hline Loan officer $6 \ldots \ldots \ldots \ldots \ldots \ldots$ & 3.69 & 13.56 & 5.39 & 12.18 \\
\hline Loan officer $7 \ldots \ldots \ldots \ldots \ldots \ldots \ldots$ & 5.64 & 14.40 & 8.34 & 12.93 \\
\hline Loan officer $8 \ldots \ldots \ldots \ldots \ldots \ldots$ & -3.56 & 33.23 & -.21 & 29.83 \\
\hline Constant $\ldots \ldots \ldots \ldots \ldots \ldots \ldots \ldots$ & 36.21 & 41.04 & 23.37 & 36.88 \\
\hline Deviance .................... & 8,492 & & 8,253 & \\
\hline
\end{tabular}

Note.-Model F1 (F2) excludes loans if groups defaulted within the first (first three) scheduled monthly payment(s). Model F1 (F2): $N=740$ (733) loan observations nested in 406 (405) borrowing groups, comprising 1,884 $(1,879)$ unique members. Structural embeddedness proxies are derived from Euclidean minimum spanning trees. Two-tailed significance tests.

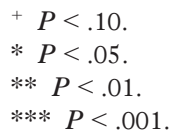

institution, the group's repayment pattern should exhibit early default rather than repayment of the majority of the loan. Data at the monthly level are used to identify groups that defaulted on their first scheduled payment (narrow filter for potential collusion) or within the first three scheduled payments (broad filter for potential collusion). Note that this is a conservative upper-bound estimate for the role of ex ante collusion because it also may include groups that genuinely failed to cooperate within the first three months. 
In the principal data set, $0.1 \%$ of loans (one case) exhibit evidence of potential strategic default within the first month of repayment. Using the broader definition, $1.1 \%$ of loans (eight cases) exhibit evidence of potential strategic default within the first three months of repayment. This indicates that the situation in which groups receive the loan disbursement and promptly stop repayment (premeditated or otherwise) is rare.

To ensure that the potentially collusive groups are not substantially affecting the principal results, the core models were rerun excluding those groups. See table F1 for the results. The substantive results were not changed.

\section{REFERENCES}

Abrams, Dominic, and Michael Hogg. 1998. "Prospects for Research in Group Processes and Intergroup Relations." Group Processes and Intergroup Relations 1 (1): 7-20.

Ahlin, Christian, and Robert Townsend. 2007. "Using Repayment Data to Test across Models of Joint Liability Lending." Economic Journal 117 (517): F11-F51.

Al-Azzam, Moh'd, R. Carter Hill, and Sudipta Sarangi. 2012. "Repayment Performance in Group Lending: Evidence from Jordan." Journal of Development Economics 97 (2): 404-14.

Albert, Robert. 1953. "Comments on the Scientific Function of the Concept of Cohesiveness." American Journal of Sociology 59 (3): 231-34.

Allison, Paul. 2014. Event History and Survival Analysis, 2d ed. Los Angeles: Sage.

Anderson, Christopher, and Louis Putterman. 2006. "Do Non-strategic Sanctions Obey the Law of Demand? The Demand for Punishment in the Voluntary Contribution Mechanism." Games and Economic Behavior 54 (1): 1-24.

Anthony, Denise. 2005. "Cooperation in Microcredit Borrowing Groups: Identity, Sanctions, and Reciprocity in the Production of Collective Goods." American Sociological Review 70 (3): 496-515.

Anthony, Denise, and Christine Horne. 2003. "Gender and Cooperation: Explaining Loan Repayment in Micro-Credit Groups." Social Psychologv Ouarterlv 66 (3): 293302.

Ardener, Shirley. 1964. "The Comparative Study of Rotating Credit Associations." Journal of the Roval Anthropological Institute of Great Britain and Ireland 94 (2): 201-29.

Armendáriz, Beatriz, and Jonathan Morduch. 2010. The Economics of Microfinance, 2 d ed. Cambridge, Mass.: MIT Press.

Ashforth, Blake, and Fred Mael. 1989. "Social Identity Theory and the Organization." Academy of Management Review 14 (1): 20-39.

Axelrod, Robert. 1986. "An Evolutionary Approach to Norms." American Political Science Review 80 (4): 1095-111.

Baldassarri, Delia. 2015. "Cooperative Networks: Altruism, Group Solidarity, Reciprocity, and Sanctioning in Ugandan Producer Organizations." American Journal of Sociology 121 (2): 355-95.

Bansal, Shweta, Sanjukta Bhowmick, and Prashant Paymal. 2011. "Fast Community Detection for Dynamic Complex Networks." Complex Networks 116:196-207.

Berg, Bruce, and Howard Lune. 2011. Qualitative Research Methods for the Social Sciences, 8th ed.. Boston: Pearson.

Berkowitz, Leonard. 1968. "Responsibility, Reciprocity, and Social Distance in HelpGiving: An Experimental Investigation of English Social Class Differences." Journal of Experimental Social Psvchologv 4 (1): 46-63.

Bernhard, Helen, Ernst Fehr, and Urs Fischbacher. 2006. "Group Affiliation and Altruistic Norm Enforcement.” American Economic Review 96 (2): 217-21. 


\section{American Journal of Sociology}

Besley, Timothy, and Stephen Coate. 1995. "Group Lending, Repayment Incentives and Social Collateral." Journal of Development Economics 46 (1): 1-18.

Bettenhausen, Kenneth. 1991. "Five Years of Groups Research: What We Have Learned and What Needs to Be Addressed.” Journal of Management 17 (2): 345-81.

Blau, Peter. 1964. Exchange and Power in Social Life. London: Transaction. . 1977. Inequality and Heterogeneity: A Primitive Theory of Social Structure. New York: Free Press.

Bossard, James. 1932. "Residential Propinquity as a Factor in Marriage Selection." American Journal of Sociology 38 (2): 219-24.

Bourdieu, Pierre. 1986. "The Forms of Capital." In Handbook of Theory and Research for the Sociology of Education, edited by John Richardson. Westport, Conn.: Greenwood.

Brass, Daniel, Kenneth Butterfield, and Bruce Skaggs. 1998. "Relationships and Unethical Behavior: A Social Network Perspective." Academy of Management Review 23 (1): 14-31.

Brett, John. 2006. "We Sacrifice and Eat Less: The Structural Complexities of Microfinance Participation.” Human Organization 65 (1): 8-19.

Brewer, Marilynn. 1979. "In-Group Bias in the Minimal Intergroup Situation: A Cognitive-Motivational Analysis." Psychological Bulletin 86 (2): 307-24.

Bryan, Gharad, Dean Karlan, and Jonathan Zinman. 2015. "Referrals: Peer Screening and Enforcement in a Consumer Credit Field Experiment." American Economic Journal: Microeconomics 7 (3): 174-204.

Burris, Val. 2005. "Interlocking Directorates and Political Cohesion among Corporate Elites." American Journal of Sociology 111 (1): 249-83.

Burt, Ronald. 1978. "Cohesion versus Structural Equivalence as a Basis for Network Subgroups." Sociological Methods and Research 7 (2): 189-212.

_. 1987. "Social Contagion and Innovation: Cohesion versus Structural Equivalence." American Journal of Sociology 92 (6): 1287-335.

2005. Brokerage and Closure: An Introduction to Social Capital. Oxford: Oxford University Press.

Caplow, Theodore, and Robert Forman. 1950. "Neighborhood Interaction in a Homogeneous Community." American Sociological Review 15 (3): 357-66.

Carpenter, Jeffrey. 2007. "The Demand for Punishment." Journal of Economic Behavior and Organization 62 (4): 522-42.

Cartwright, Dorwin, and Frank Harary. 1956. "Structural Balance: A Generalization of Heider's Theory." Psychological Review 63 (5): 277-93.

Cassar, Alessandra, and Bruce Wydick. 2010. "Does Social Capital Matter? Evidence from a Five-Country Group Lending Experiment." Oxford Economic Papers 62 (4): 715-39.

Chen, Yan, and Sherry Xin Li. 2009. "Group Identity and Social Preferences." American Economic Review 99 (1): 431-57.

Chong, Dennis. 1991. Collective Action and the Civil Rights Movement. Chicago: University of Chicago Press.

Chwe, Michael Suk-Young. 1999. "Structure and Strategy in Collective Action.” American Journal of Sociology 105 (1): 128-56.

Coleman, James. 1988. "Social Capital in the Creation of Human Capital." American Journal of Sociology S95-S120.

- 1990. Foundations of Social Theory. Cambridge, Mass.: Harvard University Press.

Cook, Karen, Margaret Levi, and Russell Hardin. 2009. Whom Can We Trust? How Groups, Networks, and Institutions Make Trust Possible. New York: Russell Sage.

Cowgill, Bo, Justin Wolfers, and Eric Zitzewitz. 2009. "Using Prediction Markets to Track Information Flows: Evidence from Google.” NBER Working paper, National Bureau of Economic Research, Cambridge, Mass.

Dawes, Robyn M. 1980. "Social Dilemmas.” Annual Review of Psvchology 31:169-93.

Desmond, Matthew. 2012. "Disposable Ties and the Urban Poor." American Journal of Sociology 117 (5): 1295-335. 
Downey, Liam. 2006. "Using Geographic Information Systems to Reconceptualize Spatial Relationships and Ecological Context." American Journal of Sociology 112 (2): 567-612.

Durkheim, Émile. 1893. The Division of Labor in Society. New York: Free Press

Entwisle, Barbara, Katherine Faust, Ronald Rindfuss, and Toshiko Kaneda. 2007. "Networks and Contexts: Variation in the Structure of Social Ties." American Journal of Sociologv 112 (5): 1495-533.

Eppstein, David. 2000. "Spanning Trees and Spanners." Pp. 425-62 in Handbook of Computational Geometrv, edited by I. R. Sack and I. Urrutia. Amsterdam: Elsevier.

Fehr, Ernst, and Simon Gächter. 2000. "Cooperation and Punishment in Public Goods Experiments." American Economic Review 90 (4): 980-94.

Fehr, Ernst, and Herbert Gintis. 2007. "Human Motivation and Social Cooperation: Experimental and Analytical Foundations." Annual Review of Sociology 33:43-64.

Fehr, Ernst, and Ivo Schurtenberger. 2018. "Normative Foundations of Human Cooperation." Nature Human Behaviour 2 (7): 458-68.

Feld, Scott. 1981. "The Focused Organization of Social Ties." American Journal of Sociology 86 (5): 1015-35.

Festinger, Leon, Stanley Schachter, and Kurt Back. 1950. Social Pressures in Informal Groups: A Study of Human Factors in Housing. New York: Harper.

Flache, Andreas. 2002. "The Rational Weakness of Strong Ties: Failure of Group Solidarity in a Highly Cohesive Group of Rational Agents." Journal of Mathematical Sociology 26 (3): 189-216.

Flache, Andreas, and Michael W. Macy. 1996. "The Weakness of Strong Ties: Collective Action Failure in a Highly Cohesive Group." Journal of Mathematical Sociology 21 (12): 3-28.

Frank, Kenneth. 1996. "Mapping Interactions within and between Cohesive Subgroups." Social Networks 18 (2): 93-119.

Frank, Kenneth, and Jeffrey Yasumoto. 1998. "Linking Action to Social Structure within a System: Social Capital within and between Subgroups." American Journal of Sociology 104 (3): 642-86.

Friedkin, Noah. 2004. "Social Cohesion." Annual Review of Sociology 30:409-25.

Geertz, Clifford. 1962. "The Rotating Credit Association: A 'Middle Rung' in Development." Economic Development and Cultural Change 10 (3): 241-63.

. 1973. The Interpretation of Cultures. New York: Basic.

Ghatak, Maitreesh. 1999. “Group Lending, Local Information and Peer Selection.” Journal of Development Economics 60 (1): 27-50.

Girvan, Michelle, and Mark Newman. 2002. "Community Structure in Social and Biological Networks." Proceedings of the National Academv of Sciences 99 (12): 7821-26.

Gómez-Gardeñes, Jesús, Irene Reinares, Alex Arenas, and Luis Mario Floría. 2012. "Evolution of Cooperation in Multiplex Networks." Scientific Reports 2, 620.

Gould, Roger. 1993. "Collective Action and Network Structure." American Sociological Review 58 (2): 182-96.

. 2003. "Why Do Networks Matter? Rationalist and Structuralist Interpretations." Pp. 233-57 in Social Movements and Networks: Relational Approaches to Collective Action, edited by Mario Diani and Doug McAdam. Oxford: Oxford University Press.

Granovetter, Mark. 1973. "The Strength of Weak Ties.” American Journal of Sociology 78 (6): 1360-80.

- 1985. "Economic Action and Social Structure: The Problem of Embeddedness." American Journal of Sociology 91 (3): 481-510.

Hampton, Keith, and Barry Wellman. 2001. "Long Distance Community in the Network Society: Contact and Support beyond Netville." American Behavioral Scientist 45 (3): 476-95.

Hanaki, Nobuyuki, Alexander Peterhansl, Peter S. Dodds, and Duncan J. Watts. 2007. "Cooperation in Evolving Social Networks." Management Science 53 (7): 1036-50. 


\section{American Journal of Sociology}

Hare, A. Paul, and Robert Bales. 1963. "Seating Position and Small Group Interaction." Sociometrv 26 (4): 480-86.

Hechter, Michael. 1988. Principles of Group Solidarity. Berkeley and Los Angeles: University of California Press.

Hechter, Michael, and Karl-Dieter Opp. 2001. Social Norms. New York: Russell Sage.

Heckathorn, Douglas D. 1990. "Collective Sanctions and Compliance Norms: A Formal Theory of Group-Mediated Social Control." American Sociological Reviere 55 (3): 366-84.

—. 1993. "Collective Action and Group Heterogeneity: Voluntary Provision versus Selective Incentives." American Sociological Revierw 58 (3): 329-50.

Hedström, Peter, and Peter Bearman. 2009. The Oxford Handbook of Analytical Sociology. Oxford: Oxford University Press.

Heider, Fritz. 1946. "Attitudes and Cognitive Organization." Journal of Psychology 21 (1): $107-12$.

Hermes, Niels, and Robert Lensink. 2007. "The Empirics of Microfinance: What Do We Know?" Economic Journal 117 (517): F1-F10.

Hermes, Niels, Robert Lensink, and Habteab T. Mehrteab. 2005. "Peer Monitoring, Social Ties and Moral Hazard in Group Lending Programs: Evidence from Eritrea." World Development 33 (1): 149-69.

Hill, R. Carter, William Griffiths, and Guay Lim. 2018. Principles of Econometrics, 5th ed. Hoboken, N.J.: Wiley.

Hogg, Michael. 1992. The Social Psychology of Group Cohesiveness: From Attraction to Social Identity. New York: Harvester Wheatsheaf.

Homans, George. 1950. The Human Group. New York: Harper. . 1974. Social Behavior: Its Elementary Forms. Oxford: Harcourt Brace.

Horne, Christine. 2004. "Collective Benefits, Exchange Interests, and Norm Enforcement." Social Forces 82 (3): 1037-62.

. 2007. "Explaining Norm Enforcement." Rationalitv and Societv 19 (2): 139-70.

Huberman, Michael, and Matthew Miles. 2002. The Qualitative Researcher's Companion. London: Sage.

Huppi, Monika, and Gershon Feder. 1990. "The Role of Groups and Credit Cooperatives in Rural Lending." World Bank Research Observer 5 (2): 187-204.

Karlan, Dean S. 2007. "Social Connections and Group Banking." Economic Journal 117 (517): F52-F84.

Kellerman, Aharon. 2012. Daily Spatial Mobilities: Physical and Virtual. London: Routledge.

Kevane, Michael, and Bruce Wydick. 2001. "Microenterprise Lending to Female Entrepreneurs: Sacrificing Economic Growth for Poverty Alleviation." World Development 29 (7): 1225-36.

Khandker, Shahidur, Baqui Khalily, and Zahed Khan. 1995. "Grameen Bank: Performance and Sustainability.” World Bank Discussion papers 306, World Bank, Washington, D.C.

Kim, Hyojoung, and Peter Bearman. 1997. "The Structure and Dynamics of Movement Participation." American Sociological Review 62: 70-93.

King, Gary, Robert O. Keohane, and Sidney Verba. 1994. Designing Social Inquiry: Scientific Inference in Qualitative Research. Princeton, N.J.: Princeton University Press.

Kitts, James. 2006. "Collective Action, Rival Incentives, and the Emergence of Antisocial Norms." American Sociological Review 71 (2): 235-59.

Kollock, Peter. 1998. "Social Dilemmas: The Anatomy of Cooperation." Annual Review of Sociology 24:183-214.

Latané, Bibb, James H. Liu, Andrezj Nowak, Michael Bonevento, and Long Zheng. 1995. "Distance Matters: Physical Space and Social Impact." Personalitv and Social Psvchologv Bulletin 21 (8): 795-805.

Lazega, Emmanuel, and Philippa Pattison. 1999. "Multiplexity, Generalized Exchange and Cooperation in Organizations: A Case Study." Social Networks 21 (1): 67-90. 
Leskovec, Jure, and Eric Horvitz. 2007. "Worldwide Buzz: Planetary-Scale Views on an Instant-Messaging Network.” Microsoft Research Technical report MSR-TR-2006186, Microsoft, Redmond, Wash.

Levy, Moshe, and Jacob Goldenberg. 2014. "The Gravitational Law of Social Interaction." Phvsica A: Statistical Mechanics and Its Applications 393:418-26.

Lin, Carolyn, and David Atkin. 2007. Communication Technology and Social Change: Theory and Implications. Hillsdale, N.J.: Erlbaum.

Lin, Nan. 2002. Social Capital: A Theory of Social Structure and Action. Cambridge: Cambridge University Press.

Macy, Michael. 1991. "Learning to Cooperate: Stochastic and Tacit Collusion in Social Exchange." American Journal of Sociology 97 (3): 808-84.

Macy, Michael, James Kitts, Andreas Flache, and Steve Benard. 2003. "Polarization in Dynamic Networks: A Hopfield Model of Emergent Structure." Pp. 162-73 in Dynamic Social Network Modeling and Analysis, edited by Ronald L. Breiger, Kathleen M. Carley, and Philippa Pattison. Washington, D.C.: National Academies.

Marmaros, David, and Bruce Sacerdote. 2006. "How Do Friendships Form?" Quarterly Journal of Economics 121 (1): 79-119.

Martin, John Levi, and King-To Yeung. 2006. "Persistence of Close Personal Ties over a 12-Year Period." Social Networks 28 (4): 331-62.

Marwell, Gerald, and Pamela Oliver. 1993. The Critical Mass in Collective Action: A Microsocial Theory. New York: Cambridge University Press.

Merry, Sally Engle. 1984. "Rethinking Gossip and Scandal." Pp. 302-71 in Toward a General Theory of Social Control, edited by Donald Black. New York: Academic Press.

Mill, John Stuart. 1882. A System of Logic, Ratiocinative and Inductive, 8th ed. New York: Harper.

Montgomery, Richard. 1996. "Disciplining or Protecting the Poor? Avoiding the Social Costs of Peer Pressure in Micro-Credit Schemes." Journal of International Development 8 (2): 289-305.

Moody, James, and Douglas White. 2003. "Structural Cohesion and Embeddedness: A Hierarchical Concept of Social Groups.” American Sociological Review 68 (1): 10327.

Moran, Patrick Alfred Pierce. 1950. "Notes on Continuous Stochastic Phenomena." Biometrika $37(1 / 2): 17-23$.

Morduch, Jonathan. 1999. "The Microfinance Promise." Journal of Economic Literature 37 (4): $1569-614$.

Nikiforakis, Nikos. 2008. "Punishment and Counter-punishment in Public Good Games: Can We Really Govern Ourselves?" Journal of Public Economics 92 (1-2): 91-112.

Nowak, Martin A. 2006. "Five Rules for the Evolution of Cooperation." Science 314 (5805): $1560-63$.

Nowak, Martin A., and Karl Sigmund. 1998. "Evolution of Indirect Reciprocity by Image Scoring." Nature 393:573-77.

Oliver, Pamela. 1980. "Rewards and Punishments as Selective Incentives for Collective Action: Theoretical Investigations." American Journal of Sociologv 85 (6): 1356-75.

Olson, Mancur. 1965. The Logic of Collective Action: Public Goods and the Theory of Groups. Cambridge, Mass.: Harvard University Press.

Ostrom, Elinor. 1999. "Coping with Tragedies of the Commons." Annual Review of $\mathrm{PO}_{0}$ litical Science 2 (1): 493-535.

. 2000. "Collective Action and the Evolution of Social Norms." Journal of Economic Perspectives 14 (3): 137-58.

Ostrom, Elinor, and James Walker. 2003. Trust and Reciprocity: Interdisciplinary Lessons for Experimental Research. New York: Russell Sage.

Paal, Beatrix, and Thomas Wiseman. 2011. "Group Insurance and Lending with Endogenous Social Collateral.” Journal of Development Economics 94 (1): 30-40. 


\section{American Journal of Sociology}

Paxton, Julia, Douglas Graham, and Cameron Thraen. 2000. "Modeling Group Loan Repayment Behavior: New Insights from Burkina Faso." Economic Development and Cultural Change 48 (3): 639-55.

Pletzer, Jan Luca, Daniel Balliet, Jeff Joireman, D. Michael Kuhlman, Sven C. Voelpel, and Paul Van Lange. 2018. "Social Value Orientation, Expectations, and Cooperation in Social Dilemmas: A Meta-analysis.” European Journal of Personality 32 (1): 62-83.

Polanyi, Karl. 1944. The Great Transformation. New York: Henry Holt \& Co.

Portes, Alejandro. 1998. "Social Capital: Its Origins and Applications in Modern Sociology." Annual Review of Sociology 24:1-24.

Portes, Alejandro, and Julia Sensenbrenner. 1993. "Embeddedness and Immigration: Notes on the Social Determinants of Economic Action." American Journal of Sociology 98 (6): 1320-50.

Poteete, Amy, Marco Janssen, and Elinor Ostrom. 2010. Working Together: Collective Action, the Commons, and Multiple Methods in Practice. Princeton, N.J.: Princeton University Press.

Putnam, Robert. 1993. "The Prosperous Community: Social Capital and Public Life." American Prospect 13 (4): 65-78.

Rankin, Katherine. 2002. "Social Capital, Microfinance, and the Politics of Development." Feminist Economics 8 (1): 1-24.

Reuben, Ernesto, and Arno Riedl. 2013. "Enforcement of Contribution Norms in Public Good Games with Heterogeneous Populations.” Games and Economic Behavior 77 (1): 122-37.

Rivera, Mark T., Sara B. Soderstrom, and Brian Uzzi. 2010. "Dynamics of Dyads in Social Networks: Assortative, Relational, and Proximity Mechanisms." Annual Review of Sociology 36:91-115.

Sampson, Robert. 1988. "Local Friendship Ties and Community Attachment in Mass Society: A Multilevel Systemic Model.”American Sociological Review 53 (5): 766-79.

Santos, Francisco, Jorge Pacheco, and Tom Lenaerts. 2006. "Evolutionary Dynamics of Social Dilemmas in Structured Heterogeneous Populations." Proceedings of the National Academv of Sciences 103 (9): 3490-94.

Schreiner, Mark. 2001. "Informal Finance and the Design of Microfinance." Development in Practice 11 (5): 637-40.

Small, Mario. 2011. "How to Conduct a Mixed Methods Study: Recent Trends in a Rapidly Growing Literature." Annual Review of Sociology 37:57-86.

- 2013. "Causal Thinking and Ethnographic Research." American Journal of Sociology 119 (3): 597-601.

Snijders, Tom A. B., and Roel J. Bosker. 2012. Multilevel Analysis: An Introduction to Basic and Advanced Multilevel Modeling, 2d ed. London: Sage.

Stephens, Monica, and Ate Poorthuis. 2015. "Follow Thy Neighbor: Connecting the Social and the Spatial Networks on Twitter." Computers, Environment and Urban Svstems 53:87-95

Stiglitz, Joseph E. 1990. "Peer Monitoring and Credit Markets." World Bank Economic Review 4 (3): 351-66.

Tajfel, Henri. 1974. "Social Identity and Intergroup Behaviour." Social Science Information 13 (2): 65-93.

.1981. Human Groups and Social Categories: Studies in Social Psychology. Cambridge: Cambridge University Press.

Turner, John. 1982. "Towards a Cognitive Redefinition of the Social Group." Pp. 15-40 in Social Identity and Intergroup Relations, edited by Henri Tajfel. Cambridge: Cambridge University Press.

Uzzi, Brian. 1996. "The Sources and Consequences of Embeddedness for the Economic Performance of Organizations: The Network Effect." American Sociological Review 61 (4): 674-98. 
1997. "Social Structure and Competition in Interfirm Networks: The Paradox of Embeddedness." Administrative Science Ouarterlv 42 (1): 35-67.

. 1999. "Embeddedness in the Making of Financial Capital: How Social Relations and Networks Benefit Firms Seeking Financing." American Sociological Review 64 (4): 481-505.

Varian, Hal. 1990. "Monitoring Agents with Other Agents." Journal of Institutional and Theoretical Economics 146 (1): 153-74.

Voss, Thomas. 2001. "Game-Theoretical Perspectives on the Emergence of Social Norms." Pp. 105-36 in Social Norms, edited by Michael Hechter and Karl-Dieter Opp. New York: Russell Sage.

Wasserman, Stanley, and Katherine Faust. 1994. Social Network Analysis: Methods and Applications. Cambridge: Cambridge University Press.

Weber, Max. (1922) 1978. Economy and Society: An Outline of Interpretive Sociology. Berkeley: University of California Press.

Wegener, Michael. 2013. "The Future of Mobility in Cities: Challenges for Urban Modelling." Transport Policv 29:275-82.

Wenner, Mark. 1995. "Group Credit: A Means to Improve Information Transfer and Loan Repayment Performance.” Journal of Development Studies 32 (2): 263-81.

White, Harrison C., Scott A. Boorman, and Ronald L. Breiger. 1976. "Social Structure from Multiple Networks." Pt. 1, "Blockmodels of Roles and Positions." American Journal of Sociology 81 (4): 730-80.

Woolcock, Michael. 2001. "Microenterprise and Social Capital: A Framework for Theory, Research, and Policy.” Journal of Socio-Economics 3 (2): 193-98.

Wydick, Bruce. 1999. "Can Social Cohesion Be Harnessed to Repair Market Failures? Evidence from Group Lending in Guatemala." Economic Journal 109 (457): 463-75.

Yamagishi, Toshio. 1986. "The Provision of a Sanctioning System as a Public Good." Journal of Personality and Social Psychology 51 (1): 110-16.

Yamagishi, Toshio, and Nobuyuki Takahashi. 1994. "Evolution of Norms without Metanorms." Pp. 311-26 in Social Dilemmas and Cooperation, edited by Ulrich Schulz, Wulf Albers, and Ulrich Mueller. New York: Springer.

Yenkey, Christopher. 2015. "Mobilizing a Market: Ethnic Segmentation and Investor Recruitment into the Nairobi Securities Exchange." Administrative Science Quarterly 60 (4): 561-95.

Zachary, Wayne. 1977. "An Information Flow Model for Conflict and Fission in Small Groups.” Journal of Anthropological Research 33 (4): 452-73.

Zeller, Manfred. 1998. "Determinants of Repayment Performance in Credit Groups: The Role of Program Design, Intragroup Risk Pooling, and Social Cohesion." Economic Development and Cultural Change 46 (3): 599-620.

Zhao, Dingxin. 1998. "Ecologies of Social Movements: Student Mobilization during the 1989 Prodemocracy Movement in Beijing." American Journal of Sociology 103 (6): 1493-529.

Zipf, George Kingsley. 1949. Human Behaviour and the Principle of Least Effort. Cambridge, Mass.: Addison-Wesley. 